\title{
Using Fuzzy Control for Modeling the Control Behaviour of a Human Pilot
}

\author{
Martin Gestwa \\ German Aerospace Center (DLR) - Institute of Flight Systems \\ Germany
}

\section{Introduction}

This chapter presents the use of Fuzzy Control to model the control behaviour of a human pilot during two particular flight tasks. Pilot models are used in different areas of the aeronautical research such as handling qualities, cockpit assistant systems as well as in the area of Human Factors or Human Computer Interaction. Aircraft safety analysis is closely connected with the error analysis of pilot computer interaction (see Enders (1989)). This aspect is also supported by the fact, that $55 \%$ the flight accidents are caused by human factors (see N.N. (2006)). Consequently, knowledge about human factors, for example the pilot workload, during the flight or during a particular flight task is important. For instance significant deviations during a particular fight task of a human pilot from his individual corresponding pilot model could be understood as a modification of his workload.

In general pilot models can be classified into behavioural and biomechanical models (see McRuer \& Krendel (1974), McRuer (1988) and Luckner (2010)).The biomechanical models defines the human pilot as a passive biodynamic system and concentrates on the biomechanical and neuromuscular aspects. They emulate the torso, the hip, upper arm and forearm as well as the Stick "feel system" dynamics of a human pilot (see Allan et al. (1973) Köhler (1997), Jex \& Magdaleno (1978), von der Vorst (1999) and Höhne (2000))

Behavioural models define the human pilot as a active dynamic control element. They can themsleves also be divided into the conventional and alternative concepts. Conventional concept makes use of the classical control technology to model a human pilot. Typical example of this approach are the quasi-linear model and the models based on optimal control theory as shown for instance in Hess (1990) and Hosman \& Stassen (1999). In Dooyong et al. (2003) an optimal control model of a human pilot was used to simulate pilot control activity for a particular approach trajectory. The pilot model was used to predict pilot workload for shipboard approaches in two different wind-over-deck conditions. Johnson \& Pritchett (2002) applied an adaptive control architecture to develop a generic pilot model for inner-loop attitude control.

Alternative concepts are based on soft-computing techniques such as Petri nets, expert systems, decision models, neural networks, or fuzzy-logic. For instance a neural network pilot model was proposed in Amelsberg et al. (2009) for wake vortex recovery of an aircraft during departure. Gestwa \& Viet (2009) demonstrate that neural networks can learn from a human pilot to perform a particular flight task during a flight. Furthermore, the knowledge based cockpit assistant system (CASSY) contains a Petri net based reference pilot model. 


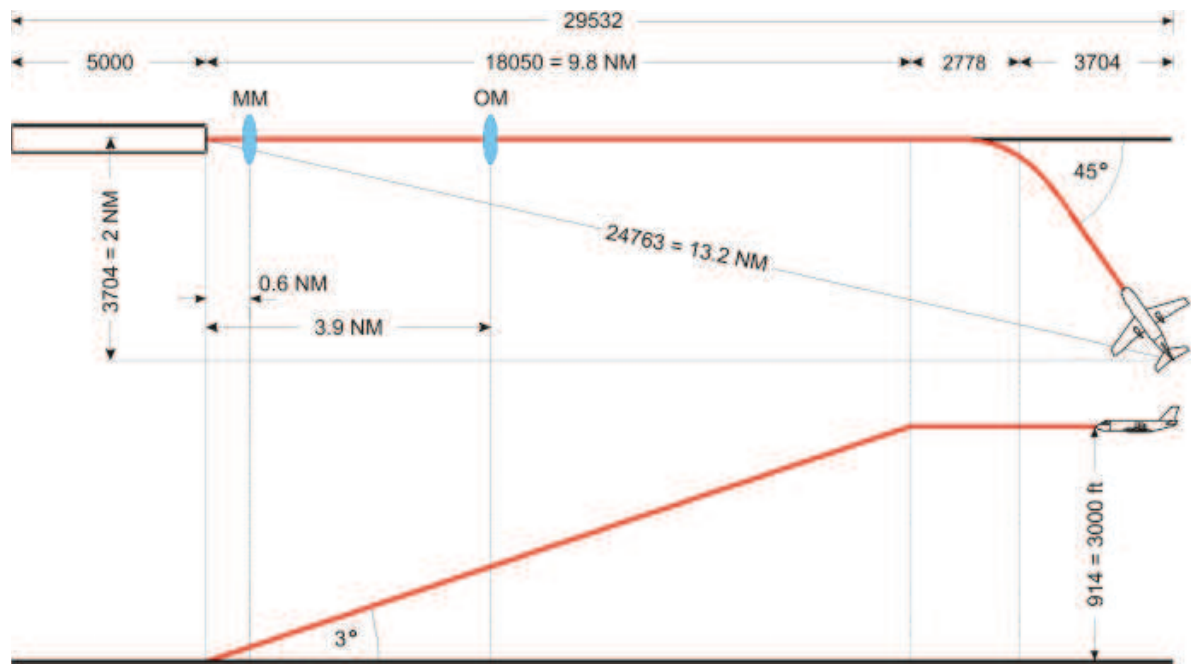

Fig. 1. ILS-Geometry

\section{Introduction to flight control during approach}

The crucial part of every flight is the approach. In particular pilot workload during approach is significantly higher than during most other phases. For this reason the two scenarios which are considered later are based on this phase.

Fig. 1 shows a typical trajectory for an approach using instrument landing system (ILS). Various types of ILS exist and are very widely used around the world. They are highly accurate means for positioning the aircraft with respect to the runway and this allow operations in poor visibility conditions. This positionings basically constis in determining two angles relatively to the ideal approach path:

- localizer (LOC) which is the lateral deviation to this path

- glide slope (GS) which is the vertical deviation to this path

(see FAA (2009) and Brockhaus (1994)). For each angle exists an corresponding indicator on the cockpit displays. Fig. 2 shows a typical primary flight display (left display ) and a typical navigation display (right display).

A precision approach is an approved descent procedure using a navigation facility aligned with a runway where glide slope information is given. When all components of the ILS system

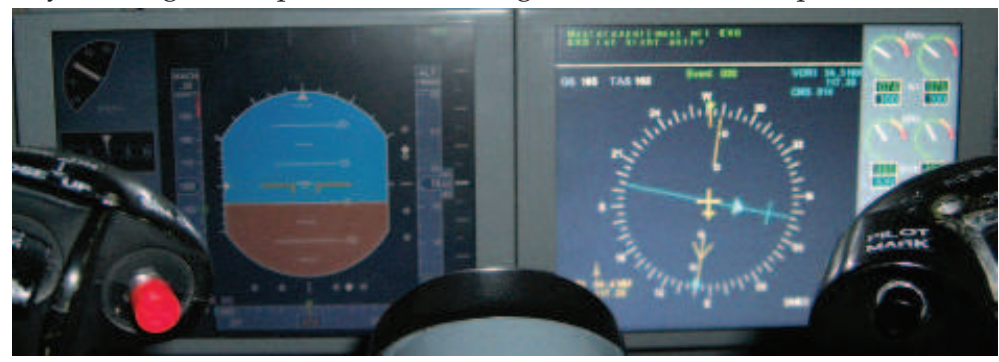

Fig. 2. Typical primary flight display and navigation display 
are available, including the approved approach procedure, the pilot may execute a precision approach. FAA (2009) contains a detailed description of an ILS.

A standard ILS-procedure is composed into five parts:

1. The pilot approaches with an offset of $45^{\circ}$ to the runway heading.

2. When the aircraft is in the visualised range of the localizer $\left(+2.5^{\circ}\right)$ the pilot initialises the interception. At the end of this maneuver, the aircraft has the right runway heading and the localizer deviation is nearly zero.

3. The next important phase begins when the aircraft is in the visualised range of the glide slope $\left(+0.5^{\circ}\right)$. Then the pilot changes the aircraft configuration. The landing flaps and slats are set to their maximum position and the gear is extended. The descent initialised and the aircraft declines with an angle of nearly $3^{\circ}$. This angle is called flight path angle.

4. Now the main task of the pilot is to keep the configured aircraft on the glide slope and the localizer with a desired speed. In this state, a slight overshooting of the speed is usually acceptable. However, an significant undershooting of the desired airspeed can lead to a dangerous flight situation. Hence, the pilot observes the speed indicator very carefully during the final approach.

5. At the end of the approach, the landing is performed. In a defined altitude, the pilot initialises the flare. He puts the thrust lever in idle position and commands a pitch up. Afterwards the main gear and a little bit later the nose gear touches down on the runway. Now, the pilot brakes the aircraft and rolls to the final position on the airport.

On order to follow this standard procedure, the pilot has several control actions to perform. Some of them are purely discrete such as flaps and slats configuration or gear extension. Others require quasi-continuous control actions such as longitudinal and lateral control. This control is achieved though a two-axis side stick, pedals and thrust command. All along this chapter the pedals will not be considered because the discussed flight tasks do not require them. The way both side stick and thrust commands change aircraft movement is briefly explained here after. The energy balance of an aircraft is the sum of kinetic and potential energy:

$$
E_{\text {total }}=E_{\text {pot }}+E_{k i n}=m g h+\frac{1}{2} m v^{2}
$$

During a short period of time $m$ is almost constant and can be considered as constant. With this assumption the potential energy only depends on the altitude and the kinetic energy only depends on the speed. If the pilot pushes the side stick, the aircraft reduces the altitude. Potential energy will be transformed in kinetic energy. Without a thrust command the energy balance is quasi constant and consequently the speed increases. According to this the pilot pulls the side stick without a thrust command. The aircraft reduces the speed and increases the altitude. The control strategy of a pilot reflects this fact and can be described as follows:

- If the pilot pulls the side stick, the corresponding thrust command results from the following aspects:

If the aircraft has a positive speed difference, no thrust is given because the climb reduces the speed difference. If the speed difference is roughly equal zero, a very small amount of thrust has to be set to hold the speed. If the aircraft has a negative speed difference, thrust has to be given because the climb will increase the existing speed difference. 
- If the pilot pushes the side stick the thrust command results from the following aspects: If the aircraft has a negative speed difference, no thrust is given because the descent reduces the speed difference. If the speed difference is roughly equal to zero, thrust has to be reduced a little bit to hold the speed. If the aircraft has a positive speed difference, thrust has to be reduced because the descent will increase the existing speed difference.

- The pilot increases only the thrust and with it the airspeed also. The engines of the aircraft, which is consider in this chapter, are beyond the center of gravity. On account of this an increment of the thrust produces a pitch up moment. To compensate this upward movement the pilot gives a small pitch down command.

- The pilot reduces only the thrust and with it the airspeed also. The aircraft pitches down, because a reduction of the thrust produces a pitch down moment. To compensate this downward movement the pilot gives a small pitch up command.

An additional important aspect is that many modern aircraft and in particular the one which is used after are equipped with a flight control system. All pilot commands are inputs of the flight control system. This system compute the necessary displacements of the control surfaces of the aircraft in order to satisfy pilots commands. The later can be differ. Furthermore, a so called rate command attitude hold command system is used. Such a command system stabilises an aircraft on a command attitude, like pitch or roll angle. Side-stick deflection defines a pitch or a roll rate. A consequence of the use of a rate command attitude hold control system is that pilots will only need to perform very short corrections taking the form of short peaks. This will be observed later on Fig. 6 and Fig. 14.

\section{The ILS tracking task}

The ILS tracking task (abbrev. ITT) is based on an instrument landing system of one virtual airport's (see Fig. 1 ) and focuses only the longitudinal motion of the aircraft. If the aircraft is established on the glide slope and has the required flight conditions, the pilot do not control activities. To compel the pilot to an active control behaviour the ITT was developed and can be described in the following way (see Bauschat (2000)):

The ITT consists of seven phases. At the beginning the aircraft flies with the target speed and established on the glide slope. After $70 \mathrm{sec}$ the glide slope transmitter shifts to a new position so that the glide slope indicator on the display in the cockpit moves downwards to its minimal deflection (see Subfigure (a) in Fig. 3). Now, the aircraft is above the glide slope, the pilot has to reduce the altitude. For this manoeuvre he has 70 seconds. After this procedure the glide slope transmitter is shifted again so that the glide slope indicator moves upward to its maximal deflection (see Subfigure (b) in Fig. 3). Now the aircraft is under the glide slope and the pilot has to climb with the aircraft. Again the pilot has 70 seconds to compensate the glide slope deviation. In the next phase the glide path indicator moves downward again, afterwards upward again etc. The whole ITT task requires 490 seconds, thereby the glide path indicator moves three times downward and three times upward in a given sequence.

A major aspect for the design of this flight task is to ensure, that the dynamic of the aircraft is sufficient to compensate the resultant altitude difference of the first transmitter shifting. With the typical $3^{\circ}$ value for the glide slope tilt angle this would be possible for the aircraft used during this work. Consequently, this tilt angle is later reduced to $1,5^{\circ}$ which ensures 


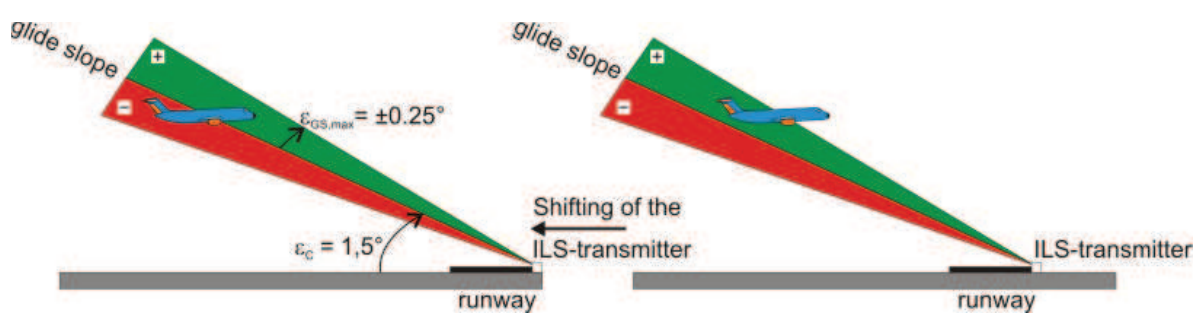

(a) Shifting of the ILS transmitter - aircaft is above the glide slope
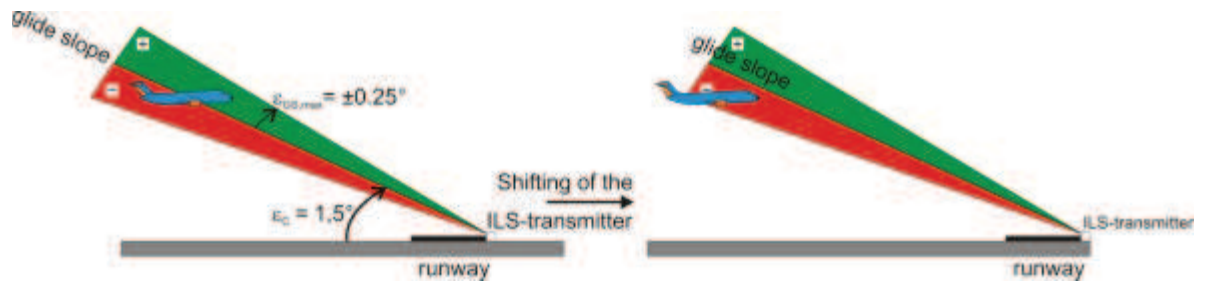

(b) Shifting of the ILS transmitter - aircaft is over the glide slope

Fig. 3. Principle of the ILS tracking Task

the feasibility of the experimental task. Furthermore, this modification implicates that the pilot has to compensate an altitude difference of $196 \mathrm{~m}$ instead of $394 \mathrm{~m}$. The shifting of the transmitter raises, that the glide slope display jumps suddenly to its maximum. The pilot senses this behaviour as unrealistic and extremely diverting. Therefore, the shifting rate of the ILS transmitter is attenuated by a first-order filter. This ensures that the glide slope indicator does not jumps but moves continuously in the direction of the current maximum deflection.

To acquire the data basis for the pilot modelling a test pilot has performed three ILS Tracking Task in a flight simulator (see Klaes (2002)). The pilot was instructed to compensate the glide slope deviation as fast as possible and if possible not to deviate from the target speed of 72 $\mathrm{m} / \mathrm{s}$ (140 kts). Furthermore, the pilot was requested to comment his own control behaviour. These comments were recorded and used for the analysis of his control behaviour as well as for the development of the individual pilot model.

\subsection{Development of the ITT-fuzzy pilot}

The pilot has to observe many instruments in the cockpit. To find out the information the human pilot uses primarily consciously and unconsciously to perform the ITT, he has to fill a questionnaire (see Rasmussen (1986)). In this questionnaire the pilot describes the priority of the instruments he needed. A given scale is divided into ten priorities, which are subdivided into three classes again (see Table 1).

This information is used to choose the measurements which will be used by the fuzzy pilot. The label numbers in Table 1 are the priorities of a professional pilot who has performed the ITT. His priorities show that for him five indicators are important to perform the ITT. By three of them the signal dynamic is important too. All very important indicators identified by means of the questionnaire in Table 1 is used for the fuzzy pilot model. The dynamics of the indicators is obtained by

$$
\Delta \dot{x}=\frac{x_{t+\Delta t}-x_{t}}{\Delta t}
$$




\begin{tabular}{|c|c|c|c|c|c|c|c|c|c|c|}
\hline \multicolumn{11}{|c|}{ (1) Priority of the instrument } \\
\hline & \multicolumn{3}{|c|}{ very important } & \multicolumn{4}{|c|}{ important } & \multicolumn{3}{|c|}{ unimportant } \\
\hline pitch & 1 & 2 & 3 & 4 & (5) & 6 & 7 & 8 & 9 & 10 \\
\hline speed trend & 1 & 2 & (3) & 4 & 5 & 6 & 7 & 8 & 9 & 10 \\
\hline speed difference & 1 & 2 & (3) & 4 & 5 & 6 & 7 & 8 & 9 & 10 \\
\hline glide slope & (1) & 2 & 3 & 4 & 5 & 6 & 7 & 8 & 9 & 10 \\
\hline flight path angle & (1) & 2 & 3 & 4 & 5 & 6 & 7 & 8 & 9 & 10 \\
\hline altitude & 1 & 2 & 3 & 4 & 5 & 6 & 7 & 8 & 9 & (10) \\
\hline vertical speed & 1 & 2 & 3 & 4 & 5 & (6) & 7 & 8 & 9 & 10 \\
\hline Distance & 1 & 2 & (3) & 4 & 5 & 6 & 7 & 8 & 9 & 10 \\
\hline \multicolumn{11}{|c|}{ (2) Priority of the instrument dynamic } \\
\hline & \multicolumn{3}{|c|}{ very important } & \multicolumn{4}{|c|}{ important } & \multicolumn{3}{|c|}{ unimportant } \\
\hline pitch & 1 & 2 & 3 & 4 & 5 & (6) & 7 & 8 & 9 & 10 \\
\hline speed trend & 1 & 2 & 3 & 4 & 5 & 6 & 7 & 8 & 9 & 10 \\
\hline speed difference & 1 & 2 & (3) & 4 & 5 & 6 & 7 & 8 & 9 & 10 \\
\hline glide slope & (1) & 2 & 3 & 4 & 5 & 6 & 7 & 8 & 9 & 10 \\
\hline flight path angle & 1 & 2 & 3 & (4) & 5 & 6 & 7 & 8 & 9 & 10 \\
\hline altitude & 1 & 2 & 3 & 4 & 5 & 6 & 7 & 8 & 9 & (10) \\
\hline vertical speed & 1 & 2 & 3 & 4 & 5 & 6 & 7 & 8 & 9 & (10) \\
\hline Distance & 1 & 2 & (3) & 4 & 5 & 6 & 7 & | 8 & 9 & 10 \\
\hline
\end{tabular}

Table 1. Questionnaire on instrument priority

Between the identified measurements exists a relation which is based on the flight dynamics and physical law. This relation can be used to reduce the number of measurements. For instance, the flight path angle can be derived from the glide slope indicator. If an aircraft is established on the glide slope, the flight path angle is equal the angle of the glide slope. Consequently the flight path angle can be disregarded as a measurement. Similarly, the distance can be derived from the sensitivity the glide slope indicator. Though the pilot consider the label information as important the aforementioned aspects can be used to reduce the numbers of measurements from seven to four. The recorded commentary of the pilot reflects that he also unconsciously reduced the parameter he constantly observe. The four chosen parameters are the glide slope indicator $\Delta \epsilon$, the derivative of the glide slope indicator $\dot{\Delta \epsilon}$, the speed difference $\Delta v$ and the derivative of the speed difference $\dot{\Delta v}$. Regarding control commands there is no possibility or need to make such a choice: the control commands of the fuzzy pilot are thus simply defined by the control elements in the cockpit. In other words the fuzzy pilot will deliver a side stick command and a thrust command.

\subsection{Specification of the linguistic terms and their fuzzy sets}

In the following subsection the definition of the linguistic terms and their associated fuzzy sets are described. As examples the glide slope derivative and the side stick command are explained in details. These definitions are based on both pilot comments and recorded flight data.

\subsubsection{Derivative of the glide slope indicator}

Fig. 4 shows the time evolution of the glide slope indicator derivative. The six movements of the glide slope transmitter are obvious. Except during a few seconds after a move of the 


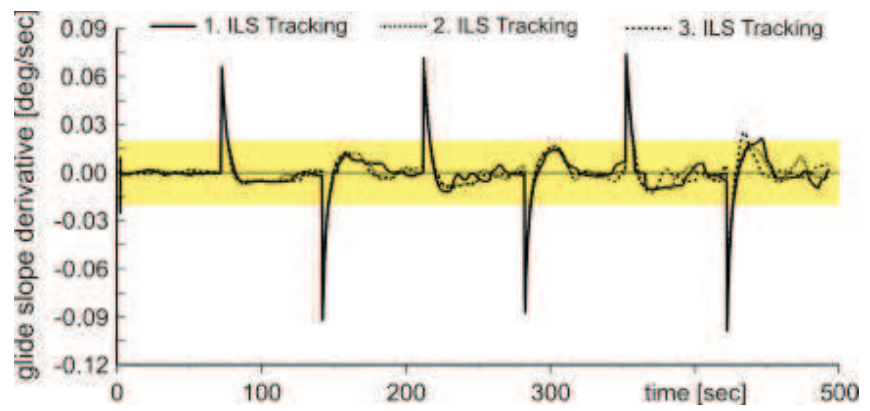

Fig. 4. Time series of the glide slope indicator derivative

glide slope transmitter, the glide slope indicator derivative is in the $\left[-0.02^{\circ} / \mathrm{sec}\right.$ to $\left.0.02^{\circ} / \mathrm{sec}\right]$ interval (identified by the yellow background in Fig. 4).

The investigation of the pilot reaction shows that he does not make any control command immediately after the glide slope transmitter starts to move. The pilot knows that he cannot follow the glide slope directly and that a new phase of the ITT starts. He waits until a quasi-stabilised situation is indicated and then starts to compensate the glide slope deviation. To model this effect the fuzzy pilot will make use of a separate controller to detect the movements of the glide slope transmitter. The measurement of this controller is the glide slope indicator derivative with the universe $\left[-0.1^{\circ} / \mathrm{s}, 0.1^{\circ} / \mathrm{s}\right]$ and in agreement with Fig. 4 the three linguistic terms below, zero and above are defined. This fuzzy set overlaps at the begin and end of the the yellow range. The definition points are provided in Table 2.

\begin{tabular}{|c|c|c|c|}
\hline$\mu$ & below & zero & above \\
\hline \hline 0 & & -0.025 & 0.015 \\
\hline 1 & -0.100 & -0.015 & 0.025 \\
\hline 1 & -0.025 & 0.015 & 0.100 \\
\hline 0 & -0.015 & 0.025 & \\
\hline
\end{tabular}

Table 2. Definition points of the fuzzy sets for the detection of the glide slope transmitter movement

The control commands of the separate controller are the two linguistic terms yes and no which indicate that the glide slope transmitter has moved. So, the rule base contains the three rules:

$\begin{array}{llll}\text { IF } & \text { IS above } & \text { THEN } & \text { shifting IS yes } \\ \text { IF } & \text { IS zero } & \text { THEN } & \text { shifting IS no } \\ \text { IF } & \text { IS below } & \text { THEN } & \text { shifting IS yes }\end{array}$

Now the linguistic terms of the glide slope derivative have to be defined in the universe $\left[-0.025^{\circ} / \mathrm{s}, 0.025^{\circ} / \mathrm{s}\right]$ (the yellow range in Fig. 4). To describe the strategy of the glide slope derivative the yellow range is enlarged in Fig. 5.

In Fig. 5 six horizontal lines and the zero line can be seen. Based on this classification the universe is divided into seven areas and each area represents a special situation. First the three areas above the zero line will be explained:

- $\left[0.01^{\circ} / s, 0.02^{\circ} / s\right]$ :

The glide slope transmitter has reached a new position. The motion of the glide slope indicator is normal. The pilot starts to stabilise the aircraft on the glide slope. 


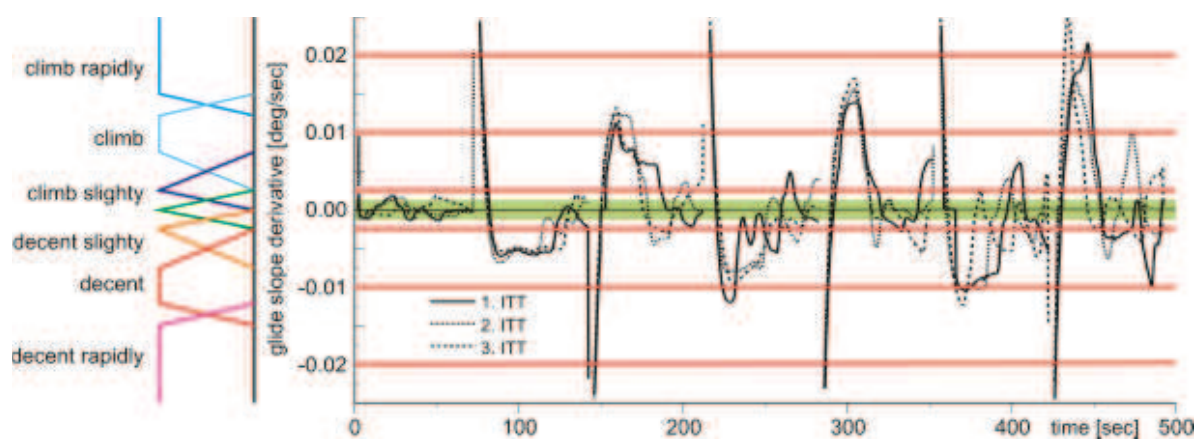

Fig. 5. Zoom of the marked range of Fig. 4

- $\left[0.0025^{\circ} / \mathrm{s}, 0.01^{\circ} / \mathrm{s}\right]$ :

The aircraft is in stationary descent or climb. The glide slope deviation is reduced.

- $\left[0.0^{\circ} / \mathrm{s}, 0.0025^{\circ} / \mathrm{s}\right]$ :

The aircraft is near to the glide slope and has to be stabilised on the glide slope. According to the commands of the pilot the aircraft oscillates around the glide slope.

$-0^{\circ} / \mathrm{s}$ :

On the glide slope the derivative should have a value of zero. Consequently the aircraft is in a stationary state.

This description can be transfered to the area below the zero line. With the help of the commentaries of the pilot seven linguistic terms can be defined. The terms are:

$$
\begin{aligned}
& \text { descent rapidly, descent, descent slightly, } \\
& \text { zero, } \\
& \text { climb slightly, climb, climb heavily }
\end{aligned}
$$

and the determining points of their fuzzy sets are summarised in Table 3.

\begin{tabular}{|l|l|l|l|l|l|l|l|}
\hline$\mu$ & $\begin{array}{l}\text { descent } \\
\text { rapidly }\end{array}$ & descent & $\begin{array}{l}\text { descent } \\
\text { slightly }\end{array}$ & zero & $\begin{array}{l}\text { climb } \\
\text { slightly }\end{array}$ & climb & $\begin{array}{l}\text { climb } \\
\text { rapidly }\end{array}$ \\
\hline \hline 0 & & -0.0150 & -0.0075 & -0.0025 & 0.0 & 0.0025 & 0.0120 \\
\hline 1 & -0.0250 & -0.0120 & -0.0025 & 0.0 & 0.0025 & 0.0075 & 0.0150 \\
\hline 1 & -0.0150 & -0.0075 & -0.0025 & 0.0 & 0.0025 & 0.0120 & 0.0250 \\
\hline 0 & -0.0120 & -0.0025 & 0.0 & 0.0025 & 0.0075 & 0.0150 & \\
\hline
\end{tabular}

Table 3. Points of the glide slope deviation

\subsubsection{Side stick command}

The side stick deflections are given as inputs to a rate-command system and Fig. 6 shows the side stick commands of an ITT. It can be seen that the pilot commands have mainly the shape of short peaks. To model this the maximum method will be used for defuzzification because this method tends to cause a pulsed behaviour (see Kruse et al. (1995) and Kahlert \& Frank (1994)). With this method the output of the fuzzy pilot is the control action corresponding to the fuzzy set having the greatest value of $\mu$. To determine the control actions an investigation of the pilot side stick commands was made and resulted in the definition of seven actions: 


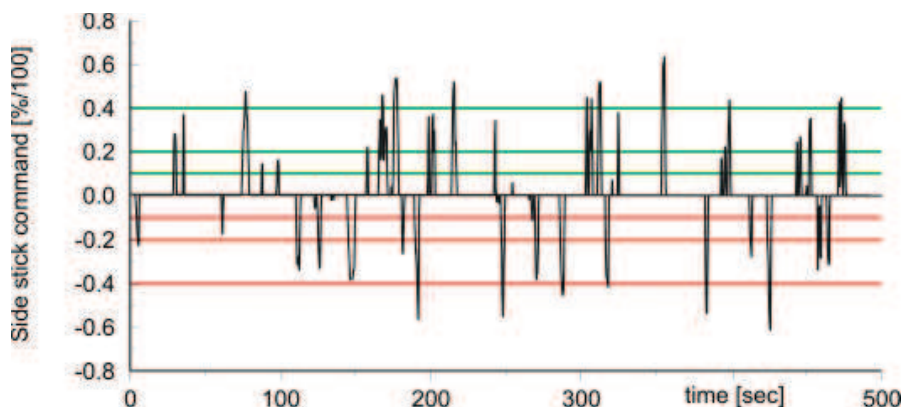

Fig. 6. Side Stick command of the pilot

null, 3 positive and 3 negative. They are represented by the horizontal green and red lines in Fig. 6.

With the values in Fig. 6 and pilot comments the corresponding linguistic terms for the side stick commands can be derived. They are:

$$
\begin{gathered}
\text { pull heavily, pull, pull slightly, } \\
\text { zero, } \\
\text { push slightly, push, push heavily }
\end{gathered}
$$

The universe of the side stick command is defined by the side stick signal with the interval $[-1,1]$. The fuzzy-sets are defined by triangular functions having their maximum exactly at a single point. The linguistic terms and the corresponding fuzzy sets are given in Table 4.

\begin{tabular}{|l|l|l|l|l|l|l|l|}
\hline$\mu$ & $\begin{array}{l}\text { pull } \\
\text { heavily }\end{array}$ & pull & $\begin{array}{l}\text { pull } \\
\text { slightly }\end{array}$ & null & $\begin{array}{l}\text { push } \\
\text { slightly }\end{array}$ & push & $\begin{array}{l}\text { push } \\
\text { heavily }\end{array}$ \\
\hline \hline 0 & -1.0 & -0.4 & -0.2 & -0.1 & 0.0 & 0.1 & 0.2 \\
\hline 1 & -0.4 & -0.2 & -0.1 & 0.0 & 0.1 & 0.2 & 0.4 \\
\hline 0 & -0.2 & -0.1 & 0.0 & 0.1 & 0.2 & 0.4 & 1.0 \\
\hline
\end{tabular}

Table 4. Points of the side stick command

The control architecture is now complete and is graphically shown in Fig. 7. The ITT rule base must however still be defined.

\subsection{Definition of the ITT-rule base}

In this section the rule base of the fuzzy pilot will be defined using the specified linguistic terms. For this the basic control strategy of the pilot should be determined from the time histories (see Fig. 8) and the pilot comments.

This strategy can be divided into three phases:

- In the first phase the glide slope transmitter is moving. The absolute value of the glide slope derivative is large. Since he knows that he cannot follow the glide slope indicator, he waits until the indication moves slowly. This behaviour is already modeled by the rule base given in section 3.2.1 on page 7 .

- In the second phase the glide slope indicator moves slowly. Now the pilot starts compensating the glide slope deviation. Depending on the actual situation he initiates a descent or climb. In this phase he is reducing the glide slope deviation very fast. He brings 


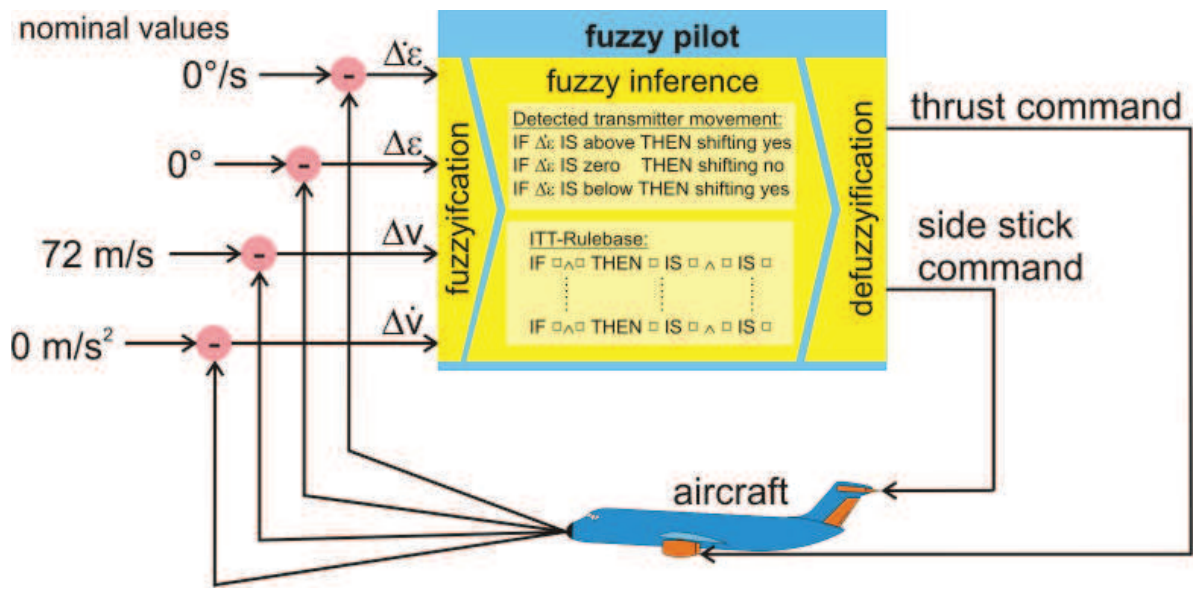

Fig. 7. Structure of the ITT fuzzy pilot

the aircraft as fast as possible close to the glide slope. During the phase of the glide slope movement the pilot only has to wait and to observe.

- In the third phase the aircraft is near the glide slope. Now the pilot has to stabilise the aircraft on the glide slope. For this procedure he stops the descent or climb by pulling or pushing the side stick. Consequently the descent or climb is interrupted and the aircraft will be stabilised on the glide slope as well as possible. Now the aircraft is approximately on the glide slope. The pilot knows that a slight side stick inputs is enough to compensated these deviations it always has except if low frequency component are 0. Furthermore he knows that these slight inputs have no effect to the airspeed.

Evaluating the airspeed difference in Fig. 8 it is remarkable that in some situation the power lever has reached the lower limit but the speed is still too high. In this situation the pilot can reduce the speed difference only with the side stick. If he pulls the side stick the aircraft interrupts the descent and the glide slope deviation is not decreasing. But it is the task of the pilot to compensate the glide slope deviation as quickly as possible. So, he has to accept the

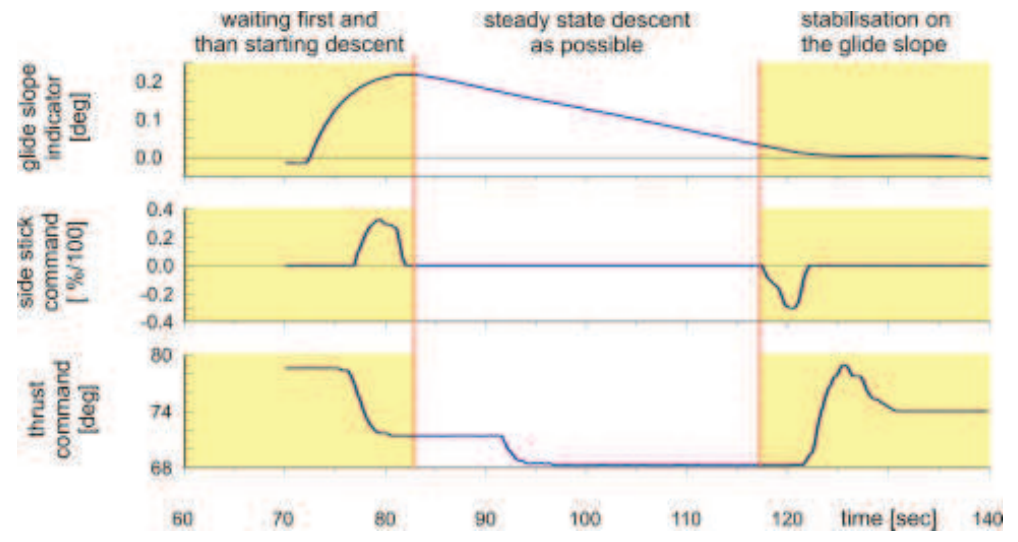

Fig. 8. Strategy of the human pilot 


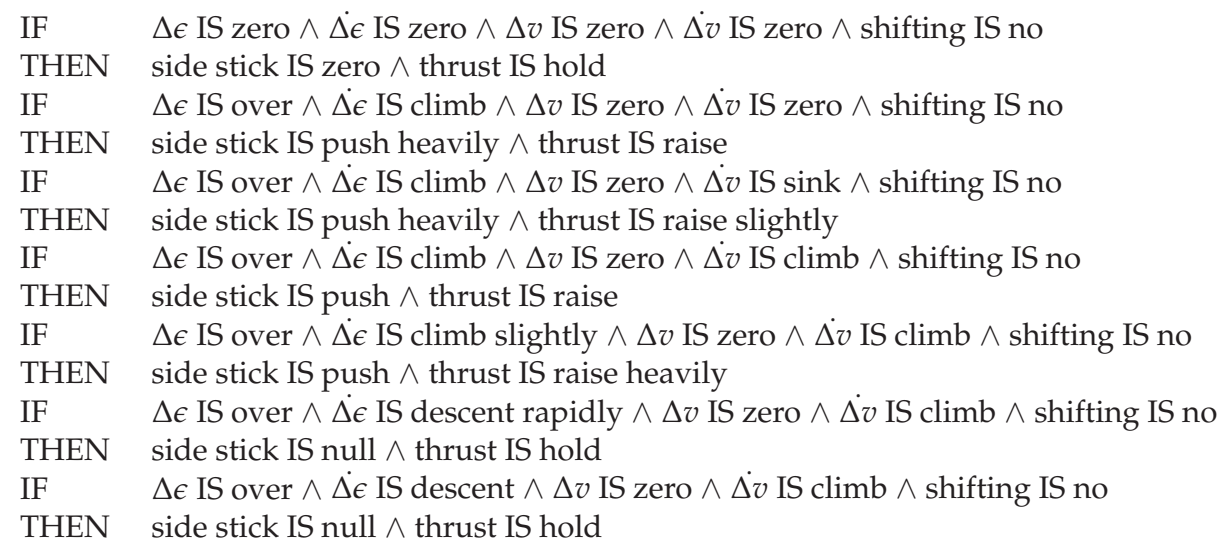

Table 5. Outline of the rule base

interim speed deviation. Here the pilot uses the relation between the side stick and thrust command, which is described in the second section 2 on page 7 .

The rule base of the fuzzy pilot has to be designed taking the above mentioned aspects into account. For the development of the rules an iterative approach is applied in order to keep the numbers of rules as low as possible. This iterative process starts with only one rule and the other rules are defined one after the other. If a situation during the ITT occurs for which the fuzzy pilot has no rule the ITT is aborted. A new rule can be defined by analysing the current flight state and this process is repeated until it does not happen anymore. Table 5 contains the result after seven iteration steps.

The control behaviour of these seven rules are shown in Fig. 9 on the base of the first movement of the glide slope transmitter. This method was used to define the whole rule base of the fuzzy pilot.

The development of the fuzzy pilot model based on the information gained from one pilot. This has the consequence, that only his specific control characteristics will be matched.
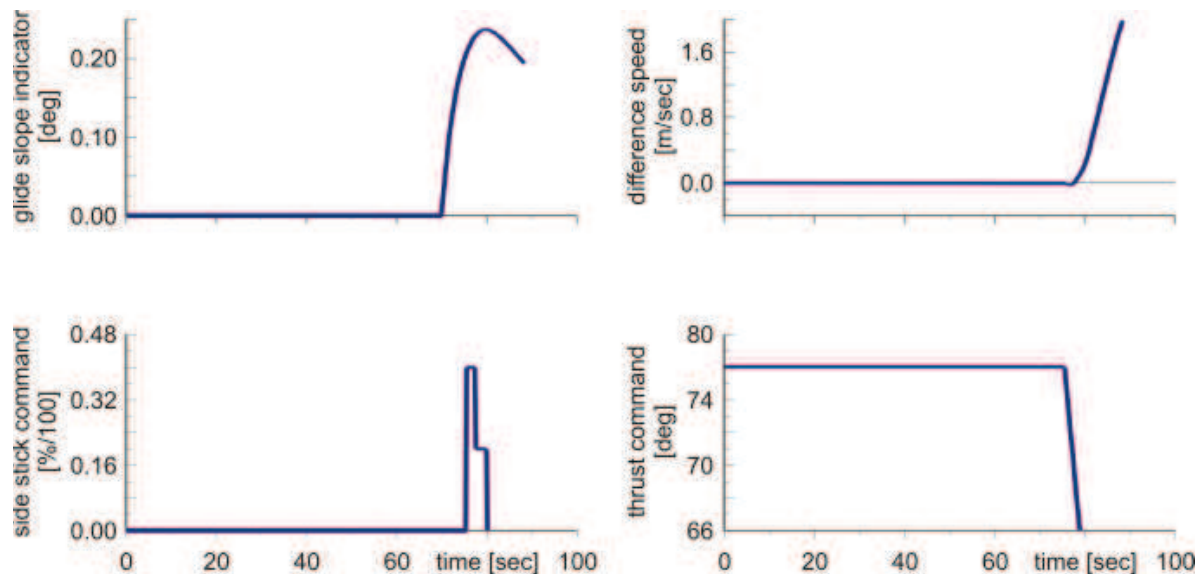

Fig. 9. A control behaviour of the fuzzy pilot by using the rule of Table 5 


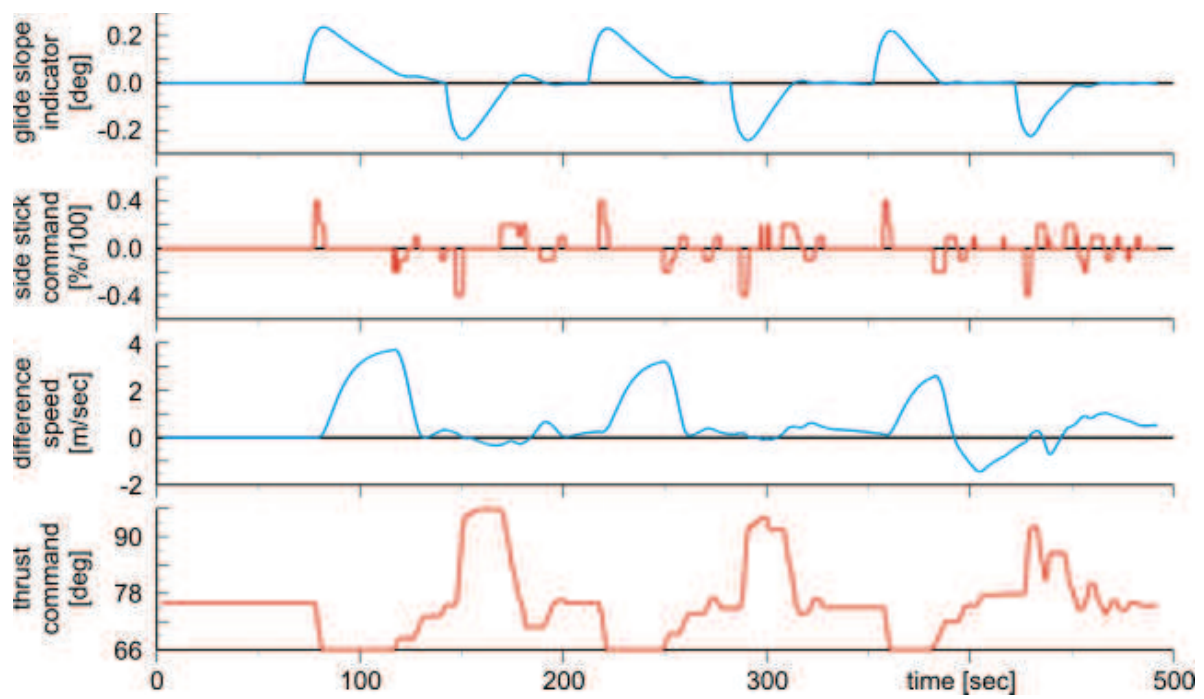

Fig. 10. Control policy of the fuzzy pilot by the ITT

\subsection{The fuzzy pilot in comparison with the human pilot}

The way the fuzzy pilot performs the ITT is shown in Fig. 10. The fuzzy logic system compensates all glide slope deviations caused by the movements of the transmitter and stabilises the aircraft on it with the demanded target speed. In order to know whether a fuzzy logic control approach is a suitable method to model the human control behaviour an assessment of the control behaviour of the fuzzy pilot in comparison with the control behaviour of the human pilot is necessary. Indeed, many factors may influence the control activities of a human pilot (see Budd (1992)). Therefore the number of experiments which are required to identify the real influence of each one of them is very high. For simplicity, only a simplified comparison is presented here.

\subsubsection{Comparison of the glide slope indicator}

To compare the glide slope indicator deviations of the human pilot and the fuzzy pilot their time evolution on the same ITT experiment may be analysed. These time evolution are shown in Fig. 11.

During the 2nd, 4th and 5th transmitter movements the two curves are matching acceptably. On the basis of the mean value and the standard deviation of the glide slope deviation it can be assessed, how well the pilot and the fuzzy pilot maintain the glide slope. Table 6 shows that all mean values can be found in the proximity of the ideal mean value zero and all standard

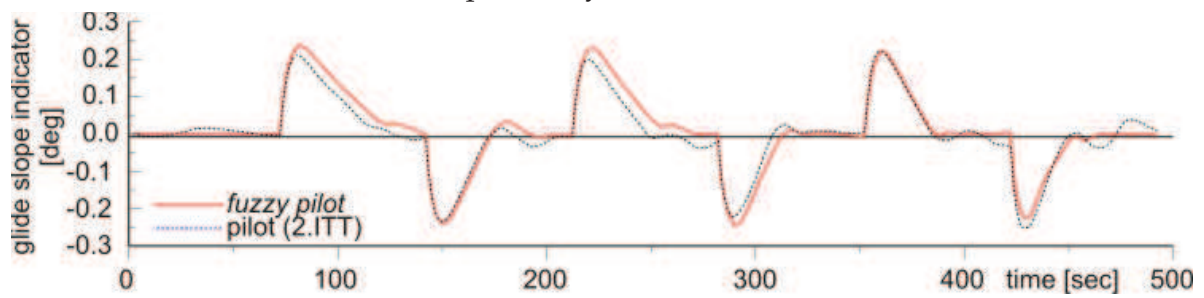

Fig. 11. Glide slope indicator deviations of the pilot (2nd ITT) and the fuzzy pilot 


\begin{tabular}{|c|c|c|c|c|}
\hline & fuzzy pilot & pilot (1st ITT) & pilot (2nd ITT) & pilot (3rd ITT) \\
\hline \hline$\mu$ & 0.00990 & 0.00083 & 0.00140 & 0.00830 \\
\hline$\sigma$ & 0.10100 & 0.10600 & 0.09400 & 0.09700 \\
\hline$\sigma_{\mu=0}$ & 0.01030 & 0.01130 & 0.00880 & 0.00950 \\
\hline
\end{tabular}

Table 6. Mean value and standard deviation of the glide slope indicator signal

deviations are almost zero, too. Indeed the first and second ITT of the human pilot is better than the fuzzy-pilot. The mean value of fuzzy pilot and the third ITT is very similar. That applies to the standard deviation, also. Consequently, the all values of fuzzy pilot are in the range of the nature bandwidth of the human pilot control activities.

\subsubsection{Comparison of the side stick commands}

Fig. 12 shows the time series of the side stick commands of the fuzzy pilot and human pilot (2nd ITT).

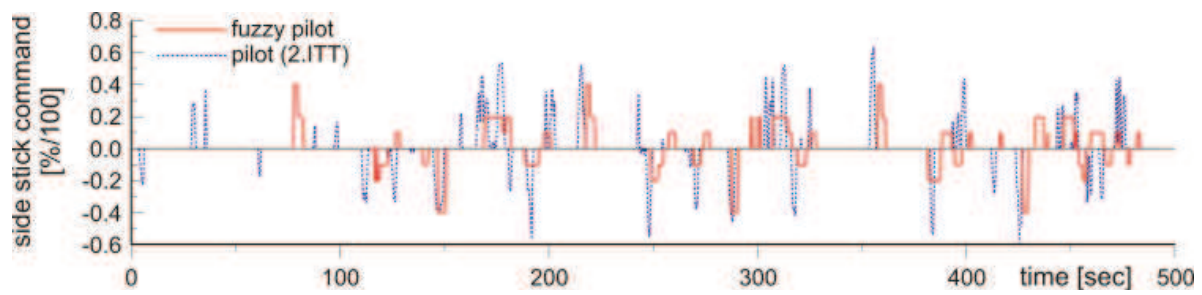

Fig. 12. Side stick command of the pilot and the fuzzy pilot

The maximum values of the side stick commands of the fuzzy pilot are rather acceptable. However, the commands of the human pilot can be characterised as jerky and short inputs in contrast to the fuzzy pilot which prefers weak and long inputs. This difference is based on the defuzzification and is typical for the maximum method. In spite of this difference the reaction of the aircraft is nearly the same (see the last section). Table 7 reflects this result, because the mean value and the standard deviation are in the range of the nature bandwidth of the human pilot control activities

\begin{tabular}{|c|c|c|c|c|}
\hline & fuzzy pilot & pilot (1st ITT) & pilot (2nd ITT) & pilot (3rd ITT) \\
\hline \hline$\mu$ & 0.00610 & 0.00680 & 0.00620 & 0.00580 \\
\hline$\sigma$ & 0.10200 & 0.14100 & 0.13600 & 0.14700 \\
\hline$\sigma_{\mu=0}$ & 0.01100 & 0.02000 & 0.01800 & 0.02200 \\
\hline
\end{tabular}

Table 7. Mean values and standard deviations of the side stick command

\subsubsection{Comparison of the control strategy}

The comparison between the human control strategy and the control strategy of the fuzzy pilot implies that the previously discussed measurements can be seen as an inherent part of a control concept. This concept defines how the pilot has to react in a situation and determine his control behaviour. During the ITT the situation is described by means of the glide slope and the speed. The control strategy is characterised by the side stick command and the thrust command. In the following example one ITT section is evaluated with respect to the control strategy. 

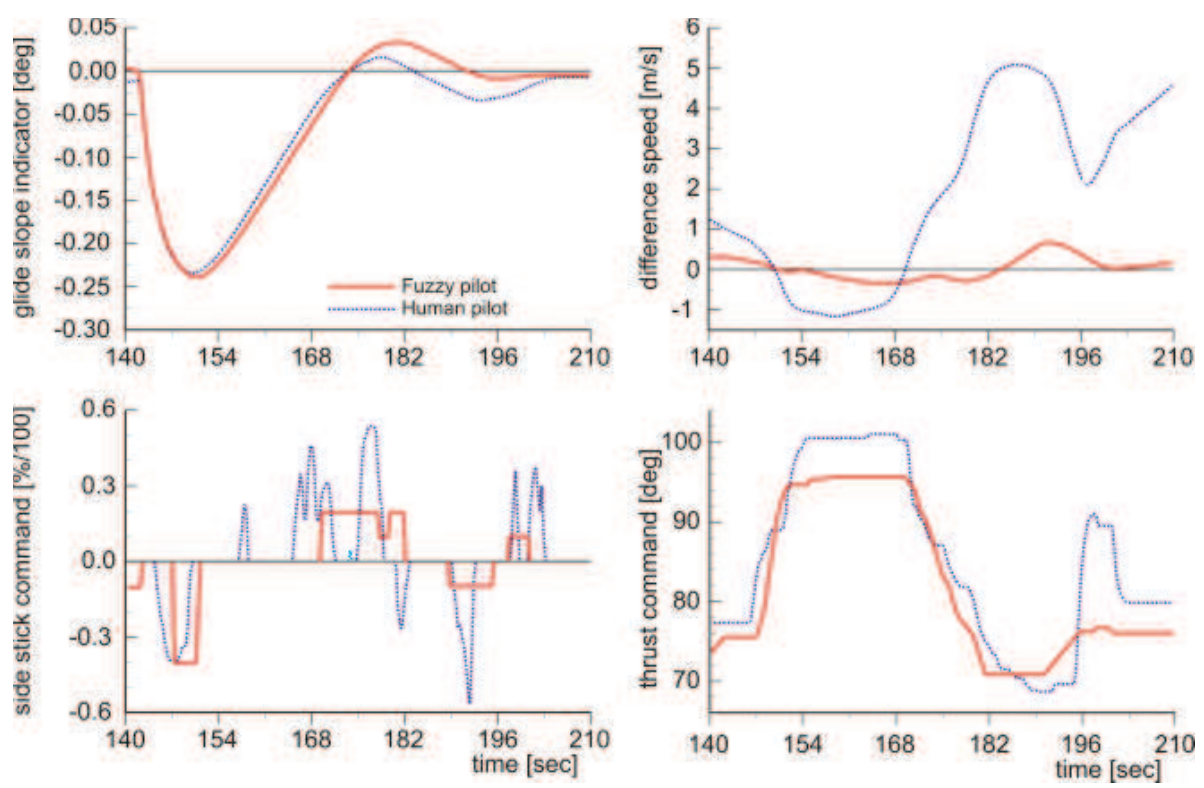

Fig. 13. Control strategy of the fuzzy pilot in comparison with the one of the human pilot

The reaction of the fuzzy pilot is very similar to the reaction of the pilot (see Fig. 13). Both react on a glide slope transmitter shifting with a stationary climb. During the stationary climb, the pilot waits until the aircraft is near the glide slope. Both begin to interrupt the climb so that the aircraft is stabilised on the glide slope. Both pilots stop the climb too late. Consequently, the aircraft overshoots the glide slope. In this situation the pilot as well as the fuzzy pilot push the side stick to return on the glide slope. In the final phase of the ITT both pilots succeed to stabilise the aircraft on the glide slope.

The coupling of the side stick and thrust command can be also observed in this section of the ITT. The commands push and thrust reduction as well as pull and thrust increase define a control unit. It is noticeable that the pilot and the fuzzy pilot has the same strategy to stabilise the aircraft on the glide slope. Both pushes the side stick but the aircraft overshoots the glide slope (see Fig. 13 from 168 to 182 seconds). The flight section in Fig. 13 points out, that the control strategy of both pilots during a negative, maximal movement of the glide slope transmitter is very similar. The previously described control strategy can be observed in every phase of the tracking task. An investigation of all opposed reactions of the fuzzy pilot and the human pilot shows that they are based on different flight states. However, both reactions are traceable and logical. Although some differences between the reaction of the human pilot and the fuzzy pilot exist, the fuzzy pilot reproduce sufficiently well control strategy of the pilot during this particular task.

\section{The localizer intercept task}

In this section a pilot model for a typical ILS approach should be developed (see Fig. 1). First, a brief description of the ILS approach is given:

The pilot begins the landing with a offset of $45^{\circ}$ to the runway. When the localizer indicator starts to move $\left(+2,5^{\circ}\right)$ the pilot initiates the intercept onto the Localizer. At the end of this 
manoeuvre the aircraft is approximately on the localizer. The next part starts when the glide slope indicator begins to run downwards $\left(+0.5^{\circ}\right)$. The pilot lowers the landing flaps and landing gear. He changes the aircraft configuration and ensures a descent of approximately $-3^{\circ}$. The aircraft is established with target speed on the localizer and on the glide slope. The ILS task ends with the beginning of the flare because the flare is excluded from this study. To develop the pilot model for this flight task a professional human pilot performs this task in a ground simulator.

The ITT can be characterised as a flight task with high control activities of the pilot because the pilot should compensate the deviations as fast as possible. It is a so called high gain task. In contrast to the ITT the ILS task can be characterised with low control activities but with high precision. Therefore, the ILS task is a so called low gain task.

Compared to the experiences with the ITT the structure of the pilot model will be different. By using the theory of the mental models from the cognitive psychology pilot model of the ILS flight task consists of simple, compact controllers (see Dutke (1994)). Each control represents a mental model and they are combined to a complex control. Similarly to classical flight controllers and control laws separate fuzzy controller will be develop for longitudinal and lateral motion. Each movement is separately considered (see Brockhaus (1994)). Furthermore, the fuzzy control of the longitudinal motion contains the thrust controlling (see section 2 on page 2 relation between side stick and thrust command). Consequently, the structure of the control is based on a two-stage controller structure. This structure reflects the strategy of the human pilot in a better way.

\subsection{Recording and Preprocessing of the Flight Test Data}

To get the knowledge and the control behaviour of a human pilot, a pilot performed ILS approaches in the ground simulator all data of these approaches were recorded. Additionally, the pilot explains his control activities and why he reacts in such a way. The comments of the pilot were recorded as well. This information is the basis for the development of the fuzzy-controller.

An initial analysis of the pilot comments and the general knowledge about the ILS approach permit to identify the measurements which are mainly used by the pilot to perform the ILS flight task:

- time, air speed, pitch angle, and rate as well as roll angle and rate, magnetic heading

- configuration of the landing flaps

- side-stick pitch and roll command as well as position of the right and left power lever

- status of the landing gear, middle, and outer marker

- localizer and glide slope deviation

These measurements can be extracted out of the flight test database.

\subsection{Development of a conventional fuzzy controller}

The first design step consists in defining the measurements and the control variables. In the case of modeling a human pilot the cockpit indicator, the cockpit input devices and the knowledge of the pilot are information sources to define the input and output variables of the fuzzy controller or rather the cognitive pilot model. All inputs of the pilot are on the primary flight- and navigation display. (see Fig. 2). As mentioned above two separate controllers are developed. The controller of the lateral motion stabilises the aircraft on the localizer whereas 


\begin{tabular}{|r|l|}
\hline Time $[\mathrm{sec}]$ & Comments of the human pilot \\
\hline 9.66 & It has been adjusted so far. \\
& And now, I simply fly until the Localizer comes in. \\
41.85 & Now, the localizer comes in. \\
44.76 & Now, I initialised the turn left, $20^{\circ}$ or so. \\
63.66 & Therefore, I finish the turn, in order to reach the desired heading \\
& without an overshoot. \\
120.45 & A little correction to the left \\
124.57 & Now, I finish the turn again. \\
148.35 & Intermediate, I check the localizer, it is o.k. \\
163.95 & Localizer is o.k. with a slight tendency to the right \\
\hline
\end{tabular}

Table 8. Typical comments of the human pilot about the lateral motion

the controller of the longitudinal motion is responsible to keep the aircraft on the glide slope and controls the airspeed.

\subsubsection{Fuzzy-controller for the lateral motion}

The pilots comments were analysed to identify which indicator on the displays are used by the pilot for the lateral control task. Table 8 summarises some typical comments about the lateral motion.

This analysis showed that the localizer indicator was the primary source of information for the lateral motion during the ILS approach. In addition to the current position the dynamic of the localizer indicator is also important (see the commentary at $41.85 \mathrm{sec}$ in Table 1). Furthermore the pilot derives out of the current localizer indicator position a roll angle, which is qualified for an enhancement of the current fight condition. For the evaluation of a roll command the roll angle gives a good orientation, because the pilot has an accurate idea of the required roll angle. Therefore, the localizer indicator deviation and its derivative as well as the roll angle is used as input for the roll controller. Additional to these inputs the status of the localizer signal is also applied as an input because this controller should only be active when the aircraft receives the localizer signal

The analysis of the flight test data has shown that only the aileron is used to control the lateral motion of the aircraft during the ILS approach and not the rudder. Furthermore, the pilot uses the localizer indicator to perform the intercept. From this fact it follows that the pilot commands only roll input to compensate localizer deviations. Table 9 summarizes the interface of the controller for the lateral motion.

The lateral motion is only controlled by the side-stick roll command. The lateral control strategy of the pilot consists of two parts. First the pilot analyses the localizer deviation. Consequently he derives a set point for the roll angle PHI_new. Then he compares this set point with the current roll angle PHI and compensates a possible difference with an adequate

\begin{tabular}{|ll|}
\hline Measurements: & \\
\hline Localizer indicator deviation & (DeltaLOC) \\
Derivation of the localizer indicator deviation & (dDeltaLOC) \\
Roll angle & (Phi) \\
Status of the localizer & (LOC_Status) \\
\hline Control variables: & \\
\hline Side-stick roll command & (SiStRollCmd)
\end{tabular}

Table 9. Interface of controller for the lateral motion 


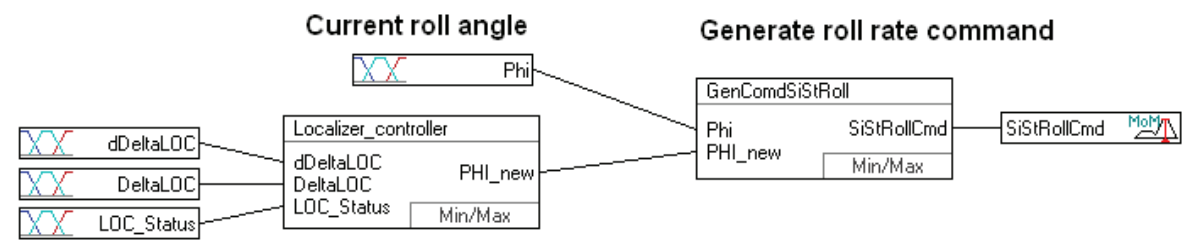

Fig. 14. Fuzzy-Controller of the Lateral Motion

roll command. Fig. 14 shows the resulting structure of the lateral fuzzy-controller.

First the localizer indicator and its derivative are interpreted by the fuzzification interface. Then, the rules of the fuzzy controller transform this information into a target roll angle, which is stored in the internal linguistic variable PHI_new. This linguistic variable and the current roll angle of the aircraft PHI are the inputs of the second fuzzy-controller which generates the corresponding side-stick command. This combination of both controller leads to a classical cascade structure which can easily be identified in Fig. 14.

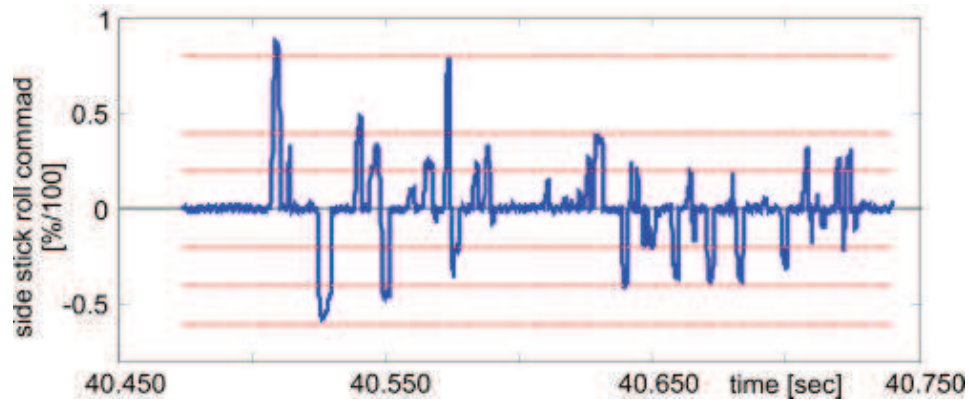

Fig. 15. Analysis of the roll commands of the human pilot

Fig. 15 shows the roll commands of the human pilot during the first ILS approach. The time history exposes that the roll commands have mainly the shape of short peaks. As already seen before this control behaviour is typical for a pilot, using a rate command system (see section 2 on page 2). To model this control behaviour the maximum method is also used for the defuzzification. The fuzzy set of this fuzzy-controler will be defined in the same way like in section 3.2.2 on page 8 describe. The red lines in Fig. 15 represents the tops of the triangle fuzzy-sets.

\subsubsection{Fuzzy-controller for the longitudinal motion}

The same method as for the lateral motion controller is applied to design the longitudinal controller. Table 10 contains the inputs and the outputs of the controller. Similarly to the lateral motion, the glide slope indicator and its dynamics are the primary information sources which are used by the pilot. Additional the deviation of the target speed is also important.

As seen in section 2 and for the ILS tracking task the control of the longitudinal motion involves the control of both pitch and airspeed. As both are strongly coupled pilots combine both actions and the fuzzy controller has to therefore also work this way. Fig. 16 shows the controller for the longitudinal motion and the airspeed.

The studies in the ground simulator have shown that the human pilot uses the thrust lever rarely. One reason for this behaviour is the knowledge about inertia of the engines. A thrust 
command needs a period until the engines reach the new commanded number of revolutions. Therefore, the human pilot moves the thrust lever carefully. In addition, it is possible that a thrust lever command is needless because a pitch command is given.

The controller uses three rule bases. The first rules basis generates an internal thrust lever command out of the difference of the target speed and the current airspeed as well as out of the airspeed tendency or dynamic. The second rule produces an internal pitch command. As inputs this rule basis uses the glide slope deviation and its derivative to model the dynamic of the indicator as well as the glide slope status. The status indicates whether the aircraft receives the glide slope signal or not. In section 2 the relation between pitch and thrust command is explained. This third rule basis combines both commands and generates the ultimate commands. The import aspect of this rule basis is to filter out unnecessary thrust lever commands. Besides, pilots effectively use such a control strategy because they know that it does not make sense to move the thrust lever every second. Thus they adapt themselves by limiting their control bandwidth for the engines which indeed corresponds to what the third rule base does this for the fuzzy-controller.

To defuzzificate the fuzzy control value into a crisp value the maxima of mean method is applied again.

Besides, the fuzzy controller outputs and the changing of aircraft configuration is an important control activity. The trigger of this activity is when the aircraft reaches the reception area of the glide slope. Then the pilot sets the landing flaps and the landing gear. Consequently, this action is a unique event during the flight task and not really a control task. Therefore, this functionality is modeled outside the fuzzy-controller and is a singular discrete procedure.

The studies in the ground simulator have shown that the pilot accepts a slight overshooting of the target speed but on no account a undershooting. Consequently, two fuzzy-sets "null"

\begin{tabular}{|ll|}
\hline Measurements: & \\
\hline $\begin{array}{l}\text { Glide slope indicator deviation } \\
\text { Derivation of the glide slope indicator deviation }\end{array}$ & (DeltaGS) \\
$\begin{array}{l}\text { Status of the glide slope } \\
\text { Target speed deviation }\end{array}$ & (GS_Status) \\
Derivation of the target speed deviation & (DeltaV) \\
\hline Control variables: & (dDeltaV) \\
\hline Side-stick pitch command & (SiStPitchCmd) \\
Thrust command & (dDeltaPLA)
\end{tabular}

Table 10. Interface of controller for the longitudinal motion

Pure side stick pitch rate command

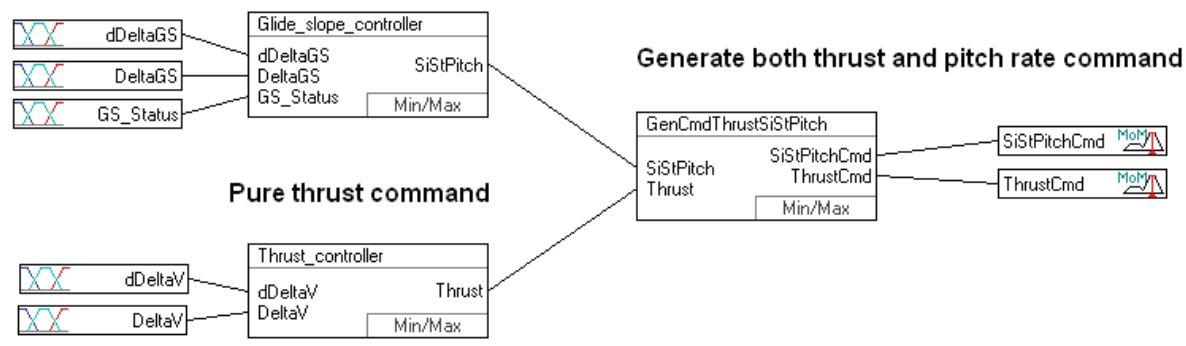

Fig. 16. Fuzzy controller of the longitudinal motion 


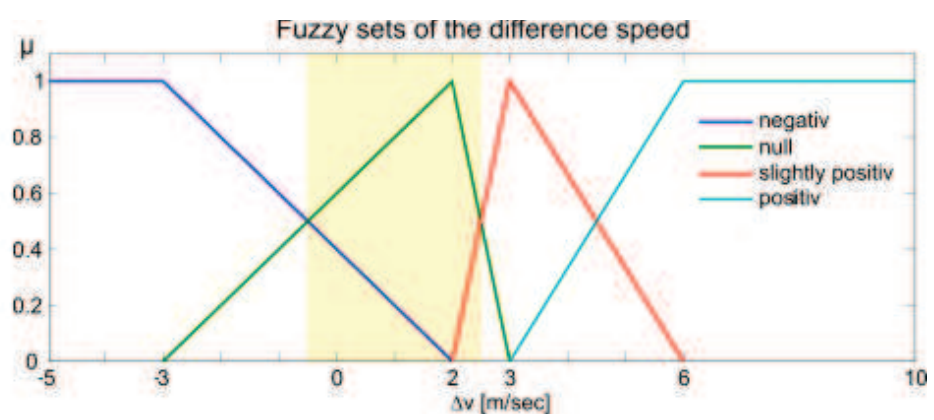

Fig. 17. Fuzzy sets of the difference airspeed

and "slightly positive" were defined to obtain such a strategy (Fig. 17).

It can observe on Fig. 17 that the fuzzy pilot has an asymmetrical tolerance range of $[-0.5 \mathrm{~m} / \mathrm{s}$, $2.5 \mathrm{~m} / \mathrm{s}$ ] which is shown by the yellow sector. $-0.5 \mathrm{~m} / \mathrm{s}$ is the intersection point to the fuzzy set "negative" and 2.5 is the intersection point to "slightly positive". The fuzzy-sets "positive", "slightly positive" and "negative" define an over- and undershooting of the target airspeed. In these cases the aircraft has an undesirable flight state and the pilot has to do some control activities.

To model the control commands of the pilot the recorded flight test data is analysed.

This procedure is also applied to define the other fuzzy-sets of the control variables.

The last design step consists in defining the rule bases. In principal, the rule base of a controller describes the physical process. In the case of modeling the control behaviour of a person or a human pilot the rule base can be interpreted as his mental model of the process or flight task. Additionally, the ILS approach to an airport is a standard flight procedure and all pilots performs it in a quite similar manner.

This knowledge can be used to define an initial subset of rules. The missing rules were defined by using an iterative process (see section 3.3). If all necessary rules were defined to perform the ILS approach the fine tuning of the rule base finished the development of the rule base. Therefore the rule base is analysed to detect gaps or weak points with fewer rules by using a debug-tool. Taking all knowledge about the ILS approach and the flight mechanics as well as flight control into account the rule base is completed. With these rule bases the fuzzy-controller is now defined.

\subsubsection{Result of the fuzzy controller}

The design fuzzy-controller was used in ILS approach simulations. For one of these simulations Fig. 18 shows the plots of the current airspeed as well as the position with respect to the localizer and glide slope. At the beginning of the simulation, the aircraft is on the left side of the localizer and flying in tis direction: the fuzzy controller has to make a turn left to catch the middle of the localizer signal. For a better understanding the airspeed is plotted against the geodetic y-coordinate as well.The default airspeed of the ILS approach was 140 kts (appr. $72 \mathrm{~m} / \mathrm{sec}$ ). The three time histories show, that the conventional ILS fuzzy-pilot performs the ILS approach. The first plot shows the airspeed. At a y-distance of $17000 \mathrm{~m}$ before the runway the ILS-fuzzy-pilot extends the landing gear. In this way he changes the aircraft configuration. Consequently the air drag is increased and the airspeed is reduced. Additionally, the ILS-fuzzy-pilot commands a pitch down command to initialise the descent. According to these control activities the airspeed increases. To keep the default airspeed the 


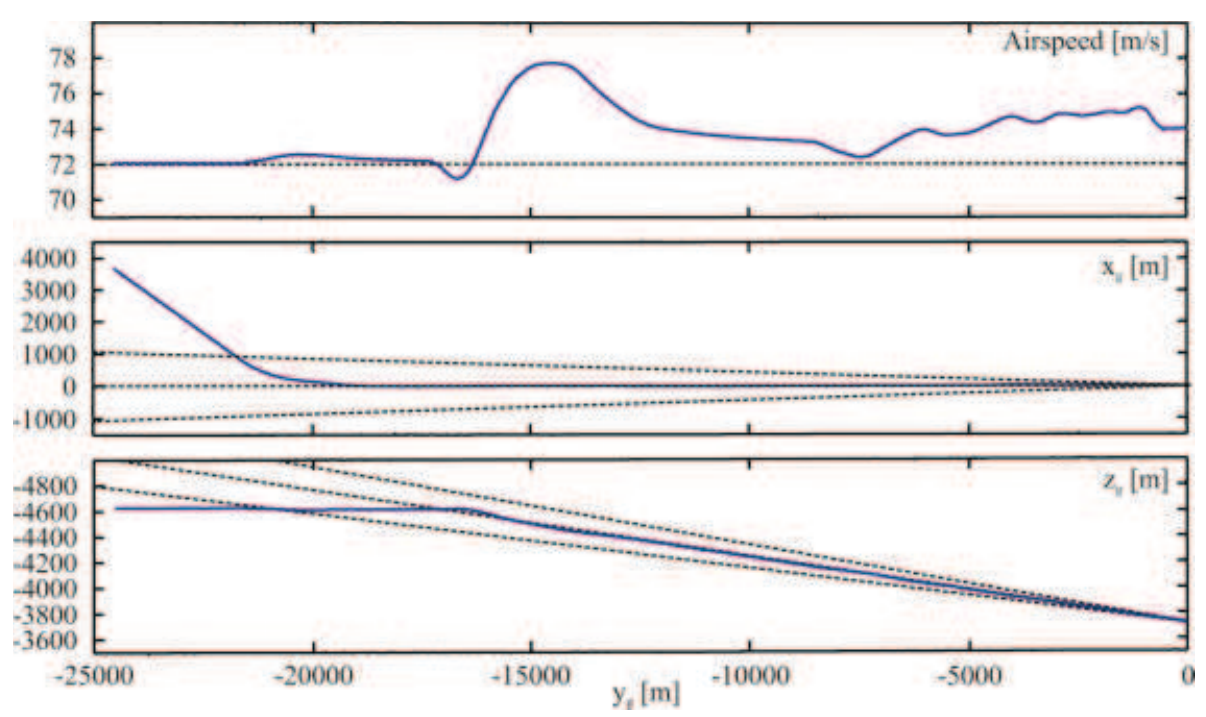

Fig. 18. ILS-approach perform by the conventional fuzzy controller

ILS-fuzzy-pilot has to reduce the thrust. The second and third plot shows the localizer and glide slope deviation. Both plots verify that the ILS-fuzzy pilot perform the ILS approach. The simulation delivers nearly the same results if the aircraft is on right side of the localizer.

\subsection{Development of a cognitive pilot model}

The aim was to develop a cognitive pilot model for an ILS approach. Therefore the structure of the above fuzzy-controller has to be modified in such a way that the fuzzy controller presumes control characteristics of the human pilot. To realise this aspect the following two modifications are made:

1. The observation of the pilot during the ILS approach in the ground simulator offered that the pilot mostly monitored the cockpit displays. With it, he supervises the flight condition of the aircraft in consideration of the ILS approach. If the current flight condition does not match the desired flight condition well enough the pilot reacts with a corresponding command input at the side stick, the thrust lever or both. This control behaviour can be interpreted as a state switching. The pilot is switching from a monitoring state to a controlling state. Indeed, every pilot has his own tolerances. This fact is the basis of the idea to develop a fuzzy-controller in combination with a finite state machine. The finite state machine is applied to model the state switching of the pilot. As noted below the state machine has the state monitoring and controlling. Between these states the corresponding transitions have to be modeled. The finite state machine starts logically in the state monitoring. In this state the pilot monitors the flight condition and he remains in this state if his evaluation of flight condition is positive. Otherwise he is switching to the state controlling and initialises a control command which is adequately to the current situation. When the control command is finished the finite state machine switch back to the state monitoring.

2. The ILS approach is a standard procedure, but each pilot has his own control characteristic. Typical characteristics are the maximum value or the duration of a control command. 


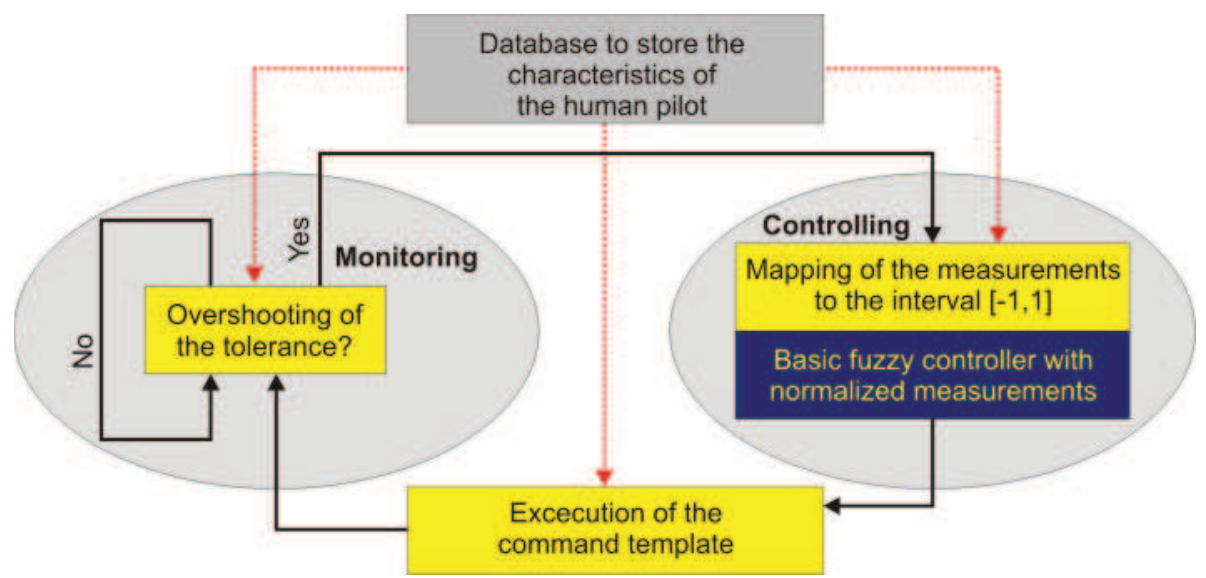

Fig. 19. Structure of the cognitive pilot model for an ILS-approach

To combine clear specified control commands with individual control characteristics the fuzzy-controller generates control command templates instead of a direct control command. These command templates are executed outside the fuzzy-controller. The fuzzy-controller does not generate a new command template as long as the last command is not finished. This technique offers the option to store the control characteristics of each pilot in a database. Furthermore, each pilot has his individual range of permissibility for each measurement. Consequently, the fuzzy-sets of the measurements have to be decoupled from the controller itself. For this purpose the fuzzy-sets are normalised to the interval $[-1,+1]$. This normalisation has to be adapted for each pilot by defining an individual mapping function.

The combination of a finite state machine with a normalised fuzzy-controller introduces the possibility to adapt the fuzzy-controller to a given control behaviour. The finite state machine models the state switching of the human pilot between monitoring and controlling. During the transition from monitoring into controlling the state machine initialises the control command which is adequately to the current situation. The fuzzy-controller generates a control command template which is corresponding to the standard procedure of the ILS-approach. This output is based on normalised measurements. Afterwards the control command template is executed. The pure fuzzy-controller is transferred to a cognitive pilot model by linking the fuzzy-controller with pilot characteristics database. Fig. 19 shows the final global structure of the cognitive pilot model.

\subsubsection{Definition of the control command templates}

The definition of the control command templates is based on the idea that all pilot commands can be approximated by triangle or trapezoid signals. These signal types are typical for a rate command system and can be divided into three phases:

1. The pilot moves the side stick from the neutral position to a given value.

2. The pilot holds this value for a time span.

3. The pilot moves the side stick back to the neutral position.

To model this kind of signal the following four parameters are required: 
1. Value of the maximum (MaxSiSt)

2. Period of time during which the pilot moves the side stick from the neutral position to the MaxSiSt value $\left(\Delta T_{\text {up }}\right)$.

3. Period of time during which the pilot holds the MaxSiSt value $\left(\Delta T_{\text {hold }}\right)$.

4. Period of time during which the pilot moves the side stick from the MaxSiSt value to the neutral position $\left(\Delta T_{\text {down }}\right)$.

During the whole ILS approach the pilot has the sidesstick during in his hand. Furthermore, the movement of the side stick is not constant and accurate. This effect is not modeled and the human pilot corrects it immediately (see at time $40.510 \mathrm{~s}$ in Fig. 15). To define all forementioned parameters a two-stage analysis is applied. First the time of the beginning and the end of the command is determined. Afterward the maximum into this time interval is computed. With this method all side-stick commands are approximated. To check the quality of this approximation the integral of the original signal and the approximated signal was computed. $\int$ sidestick $_{\text {pilot }}-$ sidestick $\left._{f u z z y}\right)^{2} d t$ The value of this integrals was small enough to justify the use of this approximation. Additionally, the aircraft flight condition is stored at the beginning and the end of the command as well.

To model the self-limitation of the control bandwidth for the engines the aforementioned method has to be varied a little bit. The human pilot knows that the engines have a delay. For this reason he generates a thrust lever deflection and waits for a moment until the engines react. Consequently, the airspeed changes very slowly. This implicit knowledge of the pilot is the reason, why an additional time delay has to be defined for the thrust lever command. Without such a restriction the fuzzy pilot would move the thrust lever to the maximum, because the slow airspeed change produces a slow reduction of the difference speed. Thereby a hustle and bustle control behaviour of the fuzzy-pilot is avoided. The real thrust control command of the fuzzy pilot is a thrust lever deflection which has to be integrated.

\subsubsection{The definition of the pilot database}

The structure of the cognitive pilot model is based on the combination of a finite state machine and a normalised fuzzy controller. To adapt this cognitive pilot model to a real human pilot the following parameters of each pilot has to be stored:

- The parameters which are mentioned in the last section

- The tolerances which have an effect on the finite state machine

- The input fuzzy sets which characterised the measurements

To define all above mentioned parameters the same technique as in section 4.2 can be used. To reduce the number of tunable parameters only normalised fuzzy sets are used to model the linguistic terms. Consequently, the apexes of the right and left neighbour fuzzy sets can be used to define the whole fuzzy set. On account of this fact only the apexes of the fuzzy sets have to be defined.

Now all parameters of the cognitive pilot model are defined and Fig. 21 shows the resulting control commands during an ILS approach.

\subsubsection{Fine tuning of the cognitive pilot by means of simulations}

An important parameter for the tuning of the cognitive pilot model is the tolerance which controls the state transition. To illustrate this three simulations are presented on Fig. 20: for 


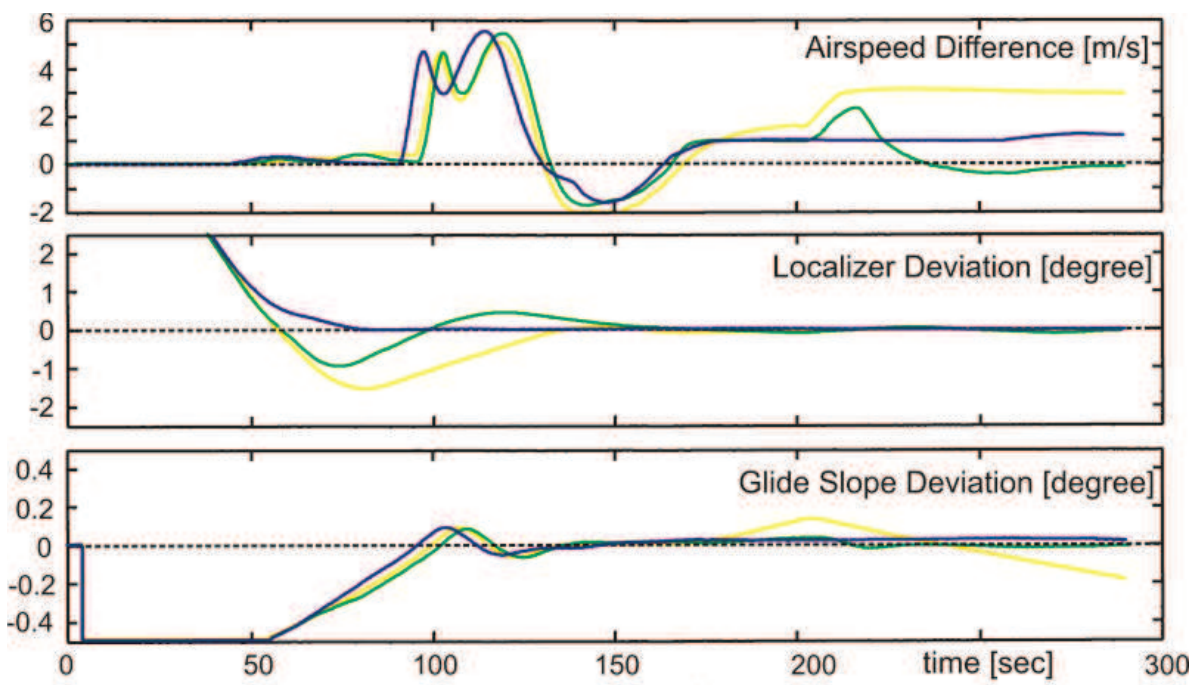

Fig. 20. Cognitive pilot model for the ILS-approach with various tolerances

the blue one the tolerance is set to 0.3 , for the green one to 0.7 , and finally for the yellow one to 0.9 .

First the ILS approach with a tolerance of 0.3 is analysed (blue line in Fig. 20). The corresponding time history of the control commands of the cognitive pilot model are shown in Fig. 21. The localizer deviation has the same behaviour as the conventional fuzzy controller of section 4.2.3. Therefore, the first activity of the cognitive pilot was to initiate the localizer interception with a heavy turn left. Afterwards he compensates the remaining localizer deviation. In the final phase of the approach the cognitive pilot model has stabilised the aircraft on the localizer.

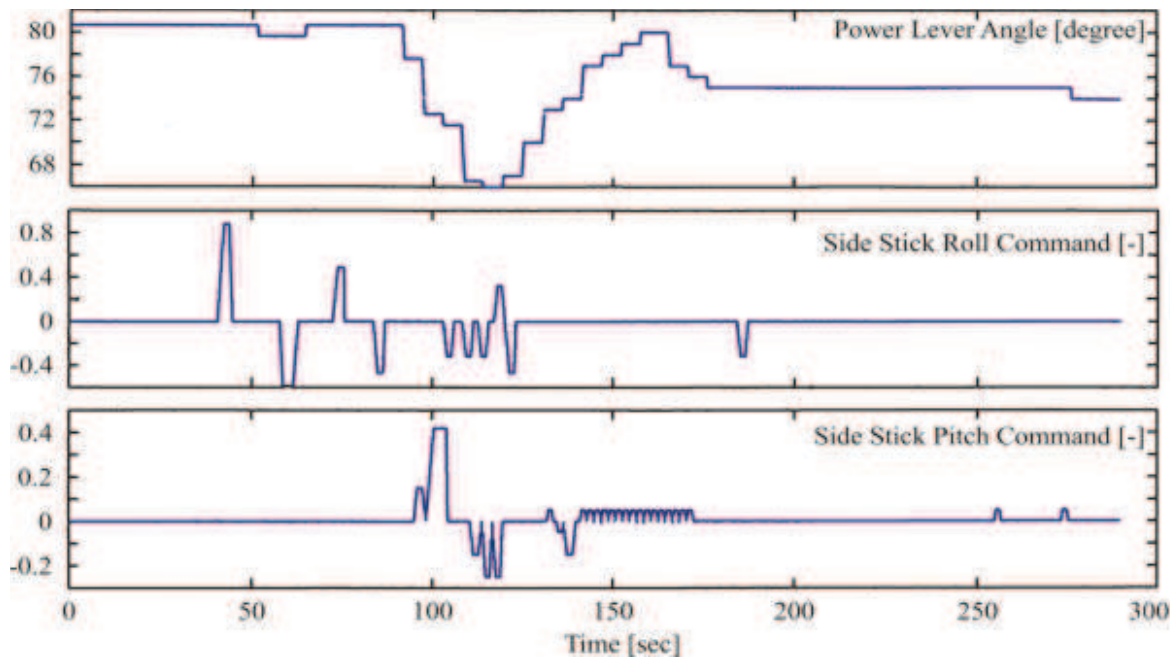

Fig. 21. Control commands of the cognitive pilot model 
His first four side stick roll commands can be interpreted as follows:

- Initiates a heavy turn left

- Concludes a heavy turn left

- Initiates a slight turn left

- Concludes a slight turn left

In the last third of the approach the cognitive pilot model makes some slight corrections to stabilise the aircraft definitely on the localizer.

The controlling of the airspeed has the some behaviour as the conventional fuzzy controller. One main aspect of the ILS standard procedure is that the human pilot extends the landing gear when the glide slope starts to move up. When the landing gear is extended the aircraft configuration changes. The new configuration defines a new target speed which is a little bit lower than the previous (in this case $135 \mathrm{kts}$ ) and the speed difference increases. Beyond this, the air drag raises and therefore the speed is reduced. After this the cognitive pilot model makes a pitch command to initialise the descent to hold the glide slope. Then again the speed difference increases. To control the speed the cognitive pilot model reduces the thrust by giving a heavy thrust command. To generate no negative difference speed the cognitive pilot model increases the thrust at 150 seconds. During the remaining approach the cognitive pilot model holds the target speed in an acceptable range, a little bit above the target speed.

The control of the glide slope deviation starts with the change of the aircraft configuration. This change is triggered when the glide slope indicator reaches the zero position. As mentioned above the cognitive pilot model makes a side stick pitch down command to initialise the descent on the glide slope. This is necessary because the aircraft is already slightly above the glide slope. The command of the cognitive pilot model was a little bit too heavy and in consequence the glide slope enters zero position too fast. Therefore the fuzzy-pilot gives a pitch up command which finally stabilises the aircraft on the glide slope with a slight deviation.

With tolerances of 0.7 and 0.9 the cognitive pilot model accepts a larger localizer deviation. A greater influence of the tolerance can be obviously observed by the glides slope and the speed difference. Therewith the influence of the finite state machine tolerance is presented clearly.

\subsection{Comparison of the cognitive pilot model and the human pilot}

The check that a cognitive pilot model can successfully perform a given flight task is relatively easy. For this purpose, only the flight test data have to be analysed, to decide whether the controller can compensate the deviation from the desired value or not (see Fig. 20 for the ILS approach). It is more difficult to decide whether a cognitive pilot model has the same control behaviour as a human controller or at least the same characteristics. One problem is in fact, that there is a fundamental difference between the control behaviour of a fuzzy-system and a human controller. If the fuzzy-system has no random component, it acts deterministically despite all fuzziness. A human pilot cannot reach this high level of determinism, because it is interfered with the following aspects:

- The ability of a human pilot to concentrate depends on his physical and psychological health.

- The environment can also influence the concentration. For instance, disturbing noise or optical stimuli can provoke mistakes.

- It is difficult for a human pilot to concentrate on many things at the same time. 
- In the cockpit of an aircraft, the human pilot gets various information at the same time and only a sequential handling can process this information.

- The response time of a human pilot is definitely longer than the response time of a fuzzy-controller.

- A human pilot is adaptive and multiple repeating of a special task improves his performance.

- It is also possible that the routine produces a slinky security feeling which can lead to negligence.

Out of these differences the following problems arise at the interpretation of the pilot behaviour:

- The human pilot can make random faulty control inputs.

- The same human pilot shows different noticeable reactions at several approaches although the same conditions predominate during all these approaches.

- The human pilot uses inadequate commands which forces him to further corrections.

The developed fuzzy-controller and the cognitive pilot model are based on an ILS approach of a human pilot. The rule base, the fuzzy-sets as well as the measurements and the control variables are extracted out of the flight test data of this approach. At first the basic strategy was realised. This strategy was adapted during the further development process to the control behaviour of the human pilot. For instance the moment when the human pilot initiates the localizer interception could be transferred in the fuzzy-pilot very well. The shapes of the command templates are not directly based on the flight test analysis. The templates were tuned during the test of the fuzzy-pilot in such a way that the resulting aircraft dynamics is equal to the dynamics which was induced by the human pilot. Therewith, the artificial pilot gets a similar behaviour like the human pilot. Consequently, the control behaviour of the cognitive pilot model includes yet characteristics of the human pilot. To compare the control behaviour of a human pilot and a cognitive pilot model a method is needed which actually describes their similarity.

In the first instance a direct comparison of their signals can be ruled out due to the non deterministic control behaviour of the human pilot. Therefore, a method has to be applied which uses a no pointwise comparison like the euclid norm or the correlation. The Dynamic Time Warping is a method to compare two data series. This method was introduced to the data mining community in Keogh \& Pazzani (1999). DTW is still widely used in various fields, e.g. bioinformatics.

Now the DTW is used to compare the control behaviour of the human pilot and the cognitive pilot model. This comparison is made in two steps. Firstly the control strategy of both pilots is intuitively compared. For this reason Fig. 22 shows both roll angle in one time history. Both pilot initialised the intersection obviously at the same time with approximately the same deflection. Furthermore the overshooting of the localizer is compensated in the same manner. It can be summarised that the control strategy of the cognitive pilot model resembled relatively well to the control strategy of the human pilot.

The second step is based on the DTW to compare parts of the ILS approach. Using this a better statement about the adaptation of the cognitive pilot model can be made. For this reason initially the lateral motion is considered, especially the moment where the localizer indicator starts to move. It ends with the stabilisation of the aircraft on the localizer. In the 


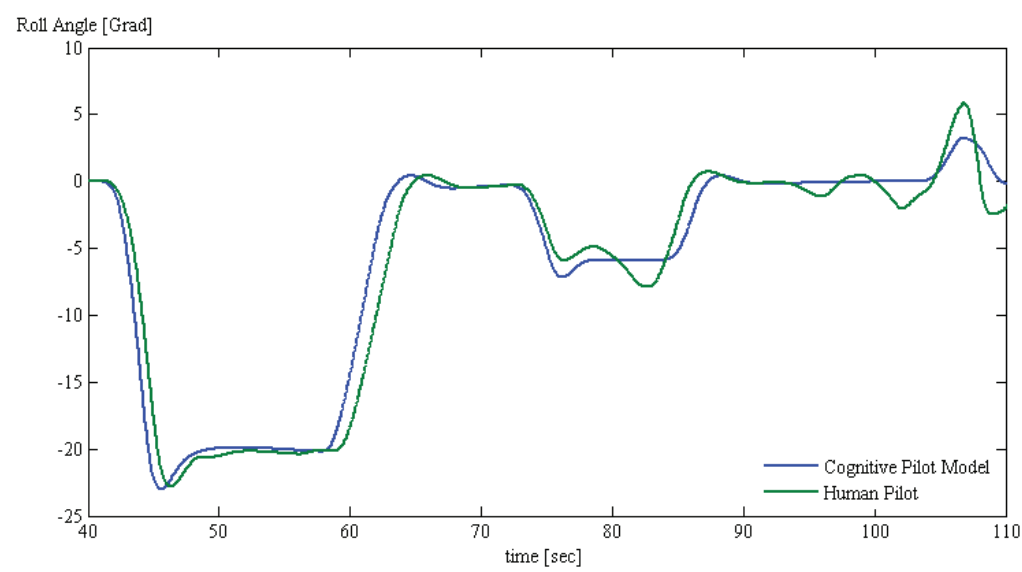

(a) Roll Angle

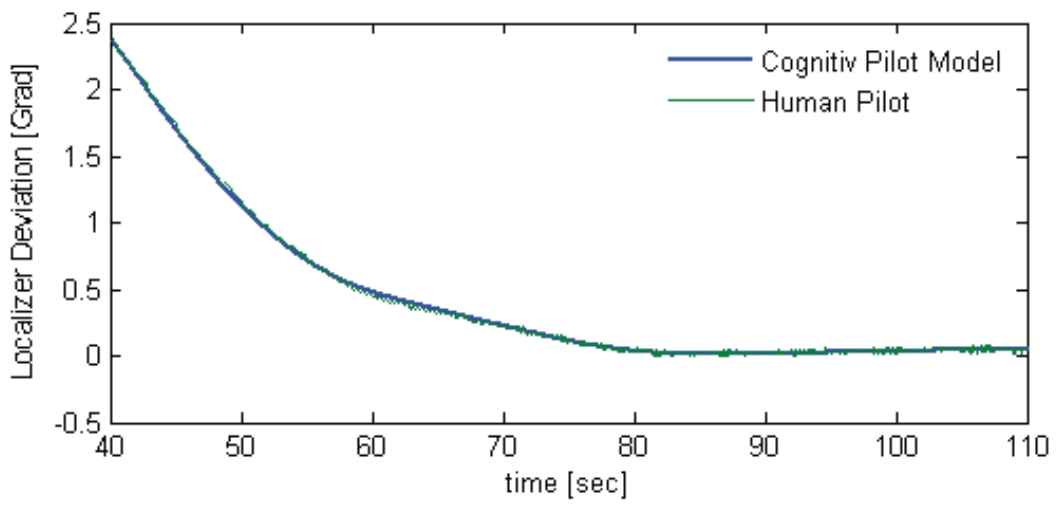

(b) Localizer deviation

Fig. 22. Comparison of the pilot model and the human Pilot

following 80 seconds, respectively a series with 2000 points, are compared and Fig. 22 shows the time series of localizer deviation of both pilots. Obviously, the cognitive pilot model is able to generate the same localizer deviation as the human pilot. This fact is confirmed by the DTW because the DTW computes the low value 0.00002739 . In addition, the reaction of the aircraft to the pilot command is compared, too.

The below time history in Fig. 22 shows the roll angle of both pilot model. These time histories are rather similar and this fact is confirmed by a low DTW value of 0.007351 . It can be summarised that the cognitive pilot model has roughly the same control behaviour like the first pilot or the first approach.

This positive result is based on the fact, that the first ILS approach is used to develop the cognitive pilot model. Consequently, both pilots have to have a great similarity. To support this simple fact the fuzzy-pilot is compared with the second ILS-approach. Fig. 23 shows the time histories of the localizer deviation and the roll angle. The intuitive comparison points 


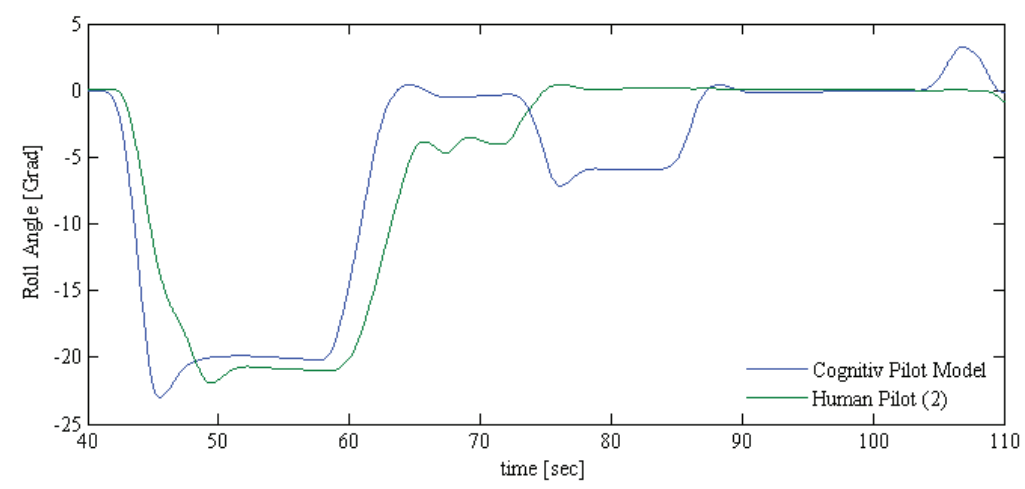

(a) Roll angle

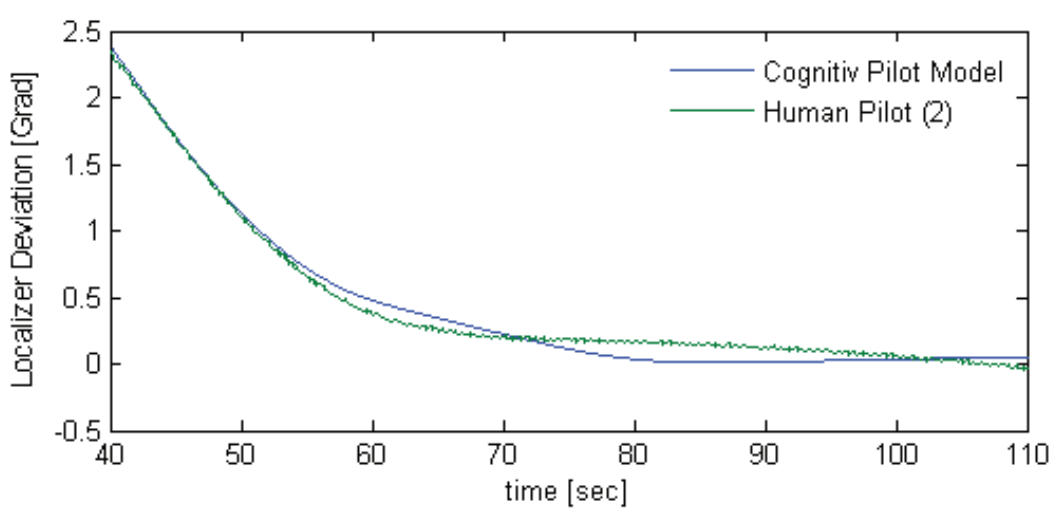

(b) Localizer deviation

Fig. 23. Comparison with the second approach

out that the cognitive pilot model and the second human pilot has slightly different control behaviour. For the localizer deviation the DTW computes a 0.0002011 and for the roll angle a 0.01894 . Therefore, the DTW reflects the first visual impression that the both pilots have a slight different control behaviour.

The DTW can be used to prove the similarity of two signals. It is indeed not possible to get direct information on how to modify the parameters of the fuzzy-controller to get a better adaptation. The absolute DTW-value is in any way not that important. Nevertheless, the DTW gives the possibility to show which data series are similar.

\section{Conclusion}

This chapter presents the use of fuzzy-control to model the control behaviour of a human pilot during a high and a low gain flight task. In both approaches the developed cognitive pilot model reproduced well the characteristics of the human pilot and it could be pointed out that: 
- The cognitive pilot models fulfil the requirements of the according flight task

- The measurements and the control commands of the pilot models and the human pilot are very similar in magnitude and trend.

- The control behaviour of the cognitive pilot models are based on the control strategy of the human pilot.

- The cognitive pilot models commands induce a similar aircraft reaction as the human pilot.

Both approaches were based on a fuzzy-controller. The rule base of the controller is an intuitive description of the controlling of the physical process and the rules are to be interpreted easily. The concrete realisation of the fuzzy-sets as a mathematical representation of the linguistic terms is depended from the variations of the individual human control behaviour.

The adaption of the pilot model to another human pilot is not easy because each pilot has to have his individual fuzzy sets. Consequently, the number of tunable parameter is large. Compared with this the pilot model of the ILS Approach based on a finite state machine and a universal fuzzy controller. To adapt this model only the parameters in the pilot database has to be fitted. Nevertheless, the second pilot model profit from the experience of the ITT task. Certainly, in both model the rule base is fixed.

In another research project of the author neural networks are used to model the control behaviour of a human pilot during a clear defined flight task (see Gestwa \& Viet (2009)). A great advantage of the neural networks are the automation of the learning. But, on the other hand the neural networks have the disadvantage that they hides their knowledge in a black box. Consequently, their interpretations are very difficult whereas they are easy in combination with a fuzzy-controller.

Based on these aspects future research project of the author will use the neural fuzzy approach or evolution strategies to optimise fuzzy-sets. An other optimisation strategy is the Ants-algorithm. In current and future research activities this work is extended to helicopters as a new platform for pilot modeling investigation.

In the field of pilot modeling the time series comparison is an important subarea. In this context further analyses are necessary. For example instead of the native DTW algorithm the DTW with Sakoe-Chiba band or with Itakura parallelogram could be used (see Salvador \& Chan (2007)). Furthermore, the Average Angle Measure could be an adequate criteria to compare two time series.

Thought the rule base is a description of the control activities which are required to perform the ITT. Furthermore, the rules are based on flight mechanic equations and for all pilots these equations are equal. Consequently it can be deduced, therefore, that for an adaption to another pilot only the fuzzy-set has to be modified and the main part of the rule base can be used unmodified.

\section{References}

Allan, R., Jex, H. \& Magdaleno, R. (1973). Manual control performance and dynamic response during sinusoidal vibration, AMRL-TR-73-78.

Amelsberg, S., Bieniek, D. \& Luckner, R. (2009). Pilot modelling for departure and wake vortex recovery using neural networks, Tagungsband - Ausgewählte Manuskripte - Deutscher Luft- und Raumfahrtkongress 2009, DGLR, Aachen, Germany , 08 - 10 September 2009; Document ID 121153. 
Bauschat, J.-M. (2000). An investigation on the dependence of pilot workload and flight simulation fidelity level, Third International Conference on Engineering Psychology and Cognitive Ergonomics - Edinburgh (25.-27.10.2000), Vol. 5, Engineering Psychology and Cognitive Ergonomics, Monterey, California, 05 - 08 August 2002; Paper No. AIAA 2002-4694.

Brockhaus, R. (1994). Flugregelung, Springer-Verlag.

Budd, H. (1992). Menschliche Zuverlässigkeit, Landsberg/ Lech: ecomed.

Dooyong, L., F., H., Sezer-Uzol, N. \& Long, L. N. (2003). Simulation of pilot control activity during helicopter shipboard operation, Atmospheric Flight Mechanics Conference and Exhibit, AIAA, Austin, Texas, 11 - 14 August 2003; Paper No. AIAA 2003-5306.

Dutke, S. (1994). Mentale Modelle Konstrukte des Wissens und Verstehen, Kognitionspsychologisches Grundlagen für die Software-Ergonomie, Verlag fr Angewandte Psychologie, Göttingen.

Enders, J. (1989). The human element - the key to safe civil operations in adverse weather, Conference Proceedings Number 470, Advisory Group of Aerospace Research and Development (AGARD), pp. K2-1 to K2-7.

FAA (2009). Instrument flying handbook - chapter 7, Federal Aviation Administration (FAA), United State of America. http://www. faa.gov/library/manuals/ aviation/instrument_flying_handbook/, cited26September2010.

Gestwa, M. \& Viet, S. (2009). Unschärfe erwnscht soft-computing methoden zur kognitiven pilotenmodellierung, Tagungsband - Deutscher Luft- und Raumfahrtkongress 2009, DGLR, Aachen, Germany , 08 - 10 September 2009.

Hess, R. A. (1990). Model for human use of motion cues in vehicular control, Journal of Guidance, Control and Dynamics Vol. 13(No. 3): 476-482.

Höhne, G. (2000). Computer aided development of biomechanical pilot models, Aerospace Science and Technology 4(1): 57 - 69.

Hosman, R. \& Stassen, H. (1999). Pilot's perception in the control of aircraft motions, Control Engineering Practice 7(11): 1421 - 1428.

Jex, H. \& Magdaleno, R. (1978). Biomechanical models for vibration feedthrough to hands and head for a semisupine pilot, Aviation, Space, and Environmental Medicine, Vol. 49(No. 1): 304-316.

Johnson, E. \& Pritchett, A. (2002). Generic pilot and flight control model for use in simulation studies, Modeling and Simulation Technologies Conference and Exhibit, AIAA, Monterey, California, 05 - 08 August 2002; Paper No. AIAA 2002-4694.

Kahlert, J. \& Frank, H. (1994). Fuzzy-Logik und Fuzzy-Control, second edn, Braunschweig; Wiesbaden: Vieweg.

Keogh, E. \& Pazzani, M. (1999). On the modelling of a human pilot using fuzzy logic control, in J. M. Zytkow \& J. Rauch (eds), 3rd European Conference on Principles and Practice of Knowledge Discovery in Databases, Vol. 1704, Springer, Prague, pp. 1-11.

Klaes, S. (2002). Attas and act/fhs system simulation for pre-flight software and hardware testing, Modeling and Simulation Technologies Conference and Exhibit, AIAA, Monterey, California, August 5-8, 2002; Paper No. AIAA 2002-4601.

Köhler, R. (1997). A new pilot model for roll ratcheting analysis, Technical Report DLR IB 11-97/32, Braunschweig.

Kruse, R., Gebhardt, J. \& Klawonn, F. (1995). Fuzzy-Systeme, $2^{n} d$ edn, Stuttgart: Teubner.

Luckner, R. (2010). Models and methods for wake vortex encounter simulations, Developments in Wake Turbulence Safety, WakeNet3 Europa - The 2nd major WakeNet3-Europe 
workshop, Airbus Premises in Toulouse on 28th and 29th of June, 2010.

McRuer, D. (1988). Pilot modeling, AGARD Lecture Series No. 157 'Advances in Flying Qualities', AGARD-LS-157, 1988.

McRuer, D. \& Krendel, E. (1974). Pilot modeling, AGARD Dografh No. 1988.

N.N. (2006). Statistical summary of commercial jet airplane accidents, worldwide operations 1959 - 2005, Airplane Safety, Boeing Commercial Airplanes, Seattle, Washington, USA.

Rasmussen, J. (1986). Information processing and human-machine interaction. An approach to cognitive engineering, Elsevier Science Publishing Co., New York, NY, U.S.A., North-Holland Series.

Salvador, S. \& Chan, P. (2007). Toward accurate dynamic time warping in linear time and space, Intelligent Data Analysis 11(5): 561 - 580.

von der Vorst, J. (1999). A pilot model for helicopter manoeuvres, NLR-TP-98448.

URL: http://www.nlr.nl/id 4639/lang en.pdf 


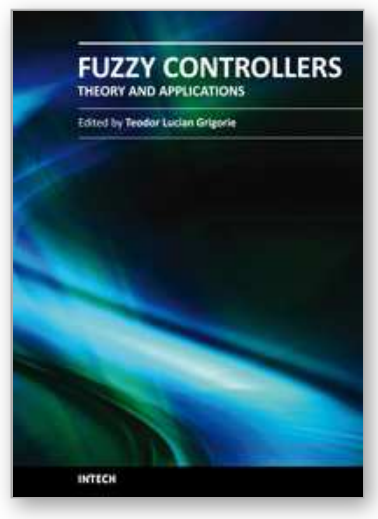

\author{
Fuzzy Controllers, Theory and Applications \\ Edited by Dr. Lucian Grigorie
}

ISBN 978-953-307-543-3

Hard cover, 368 pages

Publisher InTech

Published online 28, February, 2011

Published in print edition February, 2011

Trying to meet the requirements in the field, present book treats different fuzzy control architectures both in terms of the theoretical design and in terms of comparative validation studies in various applications, numerically simulated or experimentally developed. Through the subject matter and through the inter and multidisciplinary content, this book is addressed mainly to the researchers, doctoral students and students interested in developing new applications of intelligent control, but also to the people who want to become familiar with the control concepts based on fuzzy techniques. Bibliographic resources used to perform the work includes books and articles of present interest in the field, published in prestigious journals and publishing houses, and websites dedicated to various applications of fuzzy control. Its structure and the presented studies include the book in the category of those who make a direct connection between theoretical developments and practical applications, thereby constituting a real support for the specialists in artificial intelligence, modelling and control fields.

\title{
How to reference
}

In order to correctly reference this scholarly work, feel free to copy and paste the following:

Martin Gestwa (2011). Using Fuzzy Control for Modeling the Control Behaviour of a Human Pilot, Fuzzy Controllers, Theory and Applications, Dr. Lucian Grigorie (Ed.), ISBN: 978-953-307-543-3, InTech, Available from: http://www.intechopen.com/books/fuzzy-controllers-theory-and-applications/using-fuzzy-control-formodeling-the-control-behaviour-of-a-human-pilot

\section{INTECH}

open science | open minds

\section{InTech Europe}

University Campus STeP Ri

Slavka Krautzeka 83/A

51000 Rijeka, Croatia

Phone: +385 (51) 770447

Fax: +385 (51) 686166

www.intechopen.com

\section{InTech China}

Unit 405, Office Block, Hotel Equatorial Shanghai

No.65, Yan An Road (West), Shanghai, 200040, China

中国上海市延安西路65号上海国际贵都大饭店办公楼 405 单元

Phone: +86-21-62489820

Fax: $+86-21-62489821$ 
(C) 2011 The Author(s). Licensee IntechOpen. This chapter is distributed under the terms of the Creative Commons Attribution-NonCommercialShareAlike-3.0 License, which permits use, distribution and reproduction for non-commercial purposes, provided the original is properly cited and derivative works building on this content are distributed under the same license. 